\title{
Chromatin enrichment for proteomics in plants (ChEP-P) implicates the histone reader ALFIN-LIKE 6 in jasmonate signalling
}

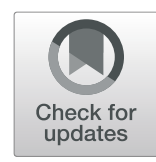

\author{
Isabel Cristina Vélez-Bermúdez $z^{1}$ and Wolfgang Schmidt1,2,3*
}

\begin{abstract}
Background: Covalent modifications of core histones govern downstream DNA-templated processes such as transcription by altering chromatin structure and function. Previously, we reported that the plant homeodomain protein ALFIN-LIKE 6 (AL6), a bona fide histone reader that preferentially binds trimethylated lysin 4 on histone 3 (H3K4me3), is critical for recalibration of cellular phosphate (Pi) homeostasis and root hair elongation under Pideficient conditions.

Results: Here, we demonstrate that AL6 is also involved in the response of Arabidopsis seedlings to jasmonic acid (JA) during skotomorphogenesis, possibly by modulating chromatin dynamics that affect the transcriptional regulation of JAresponsive genes. Dark-grown al6 seedlings showed a compromised reduction in hypocotyl elongation upon exogenously supplied JA, a response that was calibrated by the availability of Pi in the growth medium. A comparison of protein profiles between wild-type and al6 mutant seedlings using a quantitative Chromatin Enrichment for Proteomics (ChEP) approach, that we modified for plant tissue and designated ChEP-P (ChEP in Plants), yielded a comprehensive suite of chromatinassociated proteins and candidates that may be causative for the mutant phenotype.

Conclusions: Altered abundance of proteins involved in chromatin organization in al6 seedlings suggests a role of AL6 in coordinating the deposition of histone variants upon perception of internal or environmental stimuli. Our study shows that ChEP-P is well suited to gain holistic insights into chromatin-related processes in plants. Data are available via ProteomeXchange with identifier PXD026541.
\end{abstract}

Keywords: Chromatin, Histone reader, Jasmonate, Jasmonate signalling, Proteomics, Skotomorphogenesis

\section{Background}

The dynamic interplay between the incorporation of histone variants into chromatin and posttranslational modifications (PTMs) of canonical histones govern the accessibility of eukaryotic genomes by facilitating chromatin compaction or decompaction, which in turn steers downstream processes such as transcription and repair [30, 44]. Alone or in

\footnotetext{
* Correspondence: wosh@gate.sinica.edu.tw

'Institute of Plant and Microbial Biology, Academia Sinica, Taipei 11529, Taiwan

${ }^{2}$ Biotechnology Center, National Chung-Hsing University, Taichung 40227, Taiwan

Full list of author information is available at the end of the article
}

combination, histone PTMs such as acetylation, methylation, ubiquitilation or phosphorylation, coordinate a plethora of chromatin-associated events either by altering the physical environment of chromatin or by selective recruitment of effector molecules. The observation that histone PTMs can be associated with different chromatin functions led to the supposition that histone PTMs function as a language or code to govern DNA-templated processes [40], resulting in infinitive combinations that orchestrate the responses to a myriad of internal and external signals. While histone writers (e.g., acetyltransferases, methyltransferases, ubiquitin ligases, and kinases) add such modifications to histones, proteins that binds to histone PTMs (i.e., 'histone readers') harbour

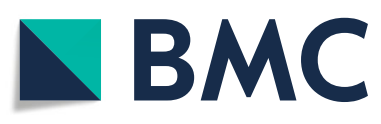

(c) The Author(s). 2021 Open Access This article is licensed under a Creative Commons Attribution 4.0 International License, which permits use, sharing, adaptation, distribution and reproduction in any medium or format, as long as you give appropriate credit to the original author(s) and the source, provide a link to the Creative Commons licence, and indicate if changes were made. The images or other third party material in this article are included in the article's Creative Commons licence, unless indicated otherwise in a credit line to the material. If material is not included in the article's Creative Commons licence and your intended use is not permitted by statutory regulation or exceeds the permitted use, you will need to obtain permission directly from the copyright holder. To view a copy of this licence, visit http://creativecommons.org/licenses/by/4.0/. The Creative Commons Public Domain Dedication waiver (http://creativecommons.org/publicdomain/zero/1.0/) applies to the data made available in this article, unless otherwise stated in a credit line to the data. 
specialized domains that recognize those modifications and direct specific downstream events. In Arabidopsis, a suite of 204 putative reader domains have been identified [40], in which members of the Royal family of domains, a structurally related group of protein folds that bind to methylated protein substrates, and PHD (plant homeodomain) fingers were shown to recognize histone lysine methylation [53]. ALFINLIKE $(A L)$ is a small, plant-specific gene family of histone readers that preferentially bind to di- or trimethylated lysin 3 of histone H3 (H3K4me3) through a conserved C-terminal PHD zinc finger $[1,24]$. The name-giving protein, Alfin 1, has been first identified as a salt stress-inducible protein in alfalfa roots [4], and subsequently in other species including Arabidopsis, which contains seven $A L$ genes [28]. In a previous study, we identified ALFIN-LIKE6 (AL6) in a genetic screen aimed at identifying mutants that are impaired in the elongation of root hairs in response to phosphate (Pi) starvation [8]. Homozygous al6 mutants are undistinguishable from the wild type under control conditions, but display a pleiotropic phenotype when grown under on Pi-deplete media, suggesting a role of AL6 (and possibly other AL proteins) in the interpretation of environmental signals. The molecular basis for the al6 phenotype remains elusive.

Jasmonic acid and its derivates, collectively called jasmonates (JAs), are lipid-derived phytohormones that regulate a plethora of responses to developmental and environmental stimuli, including pathogen defence, root development, leaf senescence, stamen development, and hypocotyl elongation [15]. Hypocotyl elongation is a critical process during skotomorphogenesis (i.e., etiolation), that, together with closed apical hooks and folded cotyledons, aids in penetrating soil layers that covers the seed after germination before exposure to light mediates the transition to photomorphogenesis and initiates autotrophy.

Photomorphogenesis triggers de-etiolation during which hypocotyl cell elongation is repressed, and induces the expression of light-dependent genes and the biosynthesis of mature chloroplasts through the action of photoreceptors. Jasmonates interrupt skotomorphogenesis by repressing the E3 ligase CONSTITUTIVE PHOTOMORPHOGENIC 1 (COP1), which is critical for its maintenance [54]. Jasmonates are perceived by the nuclear localized F-box protein CORONATINE INSENSITIVE 1 (COI1) [18], a component of a functional Skp-Cullin-F-box E3 ubiquitin ligase (SCF ${ }^{\mathrm{COI1}}$ ) complex, and activate its E3-ligase activity. In the absence of JA, JASMONATE ZIM-DOMAIN PROTEINs (JAZs), the co-repressor TOPLESS (TPL), and the adaptor protein NINJA form a complex that represses the induction of JA-responsive genes [10, 36]. Activation of SCFCoI1 results in the degradation of JAZ proteins, that activate the transcription factor MYC2 and induce the transcription of JA-responsive genes. Interestingly, MYC2 was identified as a potential target of the AL6 ortholog AL5 in a ChIP-seq approach, suggesting a link between the AL family and JA signalling.
In the present study, we explore a putative involvement of AL6 in the JA-mediated repression of skotomorphogenesis through a proteomics approach aimed at identifying proteins that may interact with AL6 in the nucleus. Since AL6 acts at the chromatin level, we adopted a Chromatin Enrichment for Proteomics (ChEP) [22] protocol that we optimized for plant tissue and designated as ChEP-P (ChEP in Plants). ChEP has been successfully employed to survey nuclear proteins in various organisms such as human cells [20, 22], mouse [45], dinoflagellates [6], and the human malaria parasite [5], but has not been applied to plants so far. In this approach, chromatin-associated proteins are in vivo cross-linked to DNA with formaldehyde, and non-covalently bound proteins are removed by washing with highly denaturing extraction buffers followed by digestion and LC-MS-MS analysis. Here, we use ChEP-P to catalogue and quantify chromatin-associated proteins of etiolated seedlings that have been exposed to media supplemented with JA. Since AL6 has been previously associated with the response to Pi deficiency [8], and Pi deficiency alters JA levels in Arabidopsis [19], we also exposed the seedlings to low Pi media and a combination of both treatments. Our ChEP-P survey revealed a suite of differentially accumulating proteins that may play important roles in JA-mediated modulation of hypocotyl elongation. We also show that AL6 is critical for JA-induced inhibition of hypocotyl elongation in etiolated Arabidopsis seedlings, possibly by compromising the transition of H3K4me3 to H3K27me3 and the deposition of the histone variant H2A.Z. We further demonstrate that this response is modulated by the availability of $\mathrm{Pi}$ in the growth media, which act antagonistically to JA on hypocotyl elongation.

\section{Results}

\section{AL6 is critical for the response of etiolated seedlings to} JA

We have previously shown that mutants defective in the expression of $A L 6$ display a pleiotropic phenotype when grown on Pi-deplete media, suggesting a role of AL6 in the interpretation of environmental cues [8]. Based on its function as a bona fine histone methylation reader, it can be assumed that AL6 has additional functions, possibly in the response to environmental or developmental conditions that alter the methylation state of lysine residues in histone H3. In the present study, we observed that etiolated al6 seedling produced hypocotyls that were significantly longer than those of the wild type and displayed a severely compromised response to exogenously applied JA. In the wild type, application of $50 \mu \mathrm{M}$ JA reduced hypocotyl length by $52.8 \%$, an effect which was markedly reduced in al6 mutant plants (Fig. 1A, B). The al6 knockdown mutant has been described 
previously (Chandrika et al., 2013). Application of JA to low Pi-grown (low $\mathrm{Pi}+\mathrm{JA}$ ) plants dampened the JAinduced growth inhibition to 37.7 and $21 \%$ in wild-type and mutant plants, respectively, indicative of altered JA signalling in Pi-deficient seedlings (Fig. 1A, B). Determination of longitudinal hypocotyl cell lengths revealed a trend towards longer cells in al6 mutants under all conditions, and a marked reduction in both wild-type and mutant plants after application of JA (Fig. 1C-E). Analysis of JA concentrations showed that, except for the anticipated increase of JA levels in JA-treated plants, no differences in internal JA levels were apparent between the genotypes, suggesting that the observed alterations in the JA response between wild-type and al6 mutant plants and among the growth types were not caused by compromised JA biosynthesis (Fig. 1F). Together, these data show that exogenously supplied JA represses skotomorphogenesis of etiolated seedlings, a response that is modulated by the Pi status of the plants. It further appears that functional AL6 is critical for a proper response of dark-grown seedlings to JA.

\section{ChEP-P identified a comprehensive subset of chromatin- associated proteins}

A ChEP-P approach was used to survey proteins that support, repress, or mediate the interplay of AL6 with chromatin. Essentially, we adopted a protocol described for mammalian cells with various alterations, which proved to be critical to make this method suitable for identifying chromatin-associated proteins in plants (Fig. 2). In particular, formaldehyde crosslinking appears to require special emphasis in the protocol for plants, necessitating a procedure which is similar to that applied for chromatin immunoprecipitation (ChIP) to avoid the dissociation of lowly abundant proteins such as transcription factors. The workflow of ChEP-P, highlighting steps that need adaptation to make this technique applicable to plants, is outlined in Fig. 2.

In total, our ChEP-P survey captured 5174 unique proteins that were identified by at least two distinct peptides with an FDR $<0.05$ when both genotypes and all growth types were considered (Supplementary Dataset S1). Under control conditions, subsets of 3343 and 2546 proteins were identified in wild-type and al6 mutant plants, respectively (Fig. 3A). Considering only proteins that were detected in two or more replicates resulted in subsets of 1425 and 1608 proteins for the genotypes under study. These numbers remained largely unchanged among the various treatments and genotypes, with large overlaps among the treatments (Fig. 3B). Only samples from al6 plants grown on low Pi media deviated from this pattern. ChEP-P of low Pi-treated al6 seedlings yielded a by $51 \%$ higher number of total proteins when compared with plants grown on Pi-replete media, and an $31 \%$ increase for low $\mathrm{Pi}+\mathrm{JA}$ vs + JA-treated al6 plants (Fig. 3A).

Gene ontology (GO) analysis of the proteins identified in two or more replicates revealed overrepresentation of the molecular process category 'jasmonic acid biosynthesis' in both genotypes treated with JA. Also, JA treatment decreased the abundance of proteins involved in translation and, albeit less pronounced, protein folding. Proteins in the category 'response to oxidative stress' were more abundant in JA-treated plants. Unexpectedly, this analysis further revealed reduced abundance of proteins related to mRNA binding and rRNA binding in JAtreated plants, the latter trend being more pronounced in wild-type plants (Fig. 3C). A more detailed analysis of the biological process revealed overrepresentation of the categories 'response to symbiotic fungus', response to wounding', 'oxylipin biosynthesis' and 'root development in JA-treated plants, proteins involved in mRNA processing were less prominent in this group of plants (Supplementary Fig. S1). Robust differences between the genotypes were not evident from this analysis.

\section{ChEP-P complements other proteomic approaches}

Our ChEP-P dataset is largely complementary to two different proteomic studies using the same material; a suite of proteins defined as the 'RNA-binding proteome' [38], and an approach aimed at identifying ubiquitinated proteins [2]. Only a relatively small subset of 71 proteins was identified in all three approaches and can thus be classified as core proteins of etiolated Arabidopsis seedlings (Fig. 4A). Curating proteins derived from the ChEP-P dataset for nuclear localization yielded a suite of 194 chromatin-associated proteins (Table 1). Of those, DNA- and RNA-binding proteins, and proteins involved in histone modifications constitute the largest fractions (Fig. 4C). Moreover, chromatin-binding proteins, DNA transcription factors, and proteins involved in DNA metabolism are better represented in the ChEP-P data set when compared to other approaches (Fig. 4B). For example, ChEP-P identified 6-fold more DNA-binding and 10-fold more chromatin-binding proteins than the study targeting RNA-binding proteins [38], suggesting that ChEP-P is suitable to provide a comprehensive catalogue of proteins that are covalently linked or transiently associated with chromatin. Gene ontology of the nuclearlocated proteins revealed pronounced overrepresentation of proteins involved in chromosome organization, DNA damage response, nucleocytoplasmic transport, RNA processing, as well as categories related to stimulus response (Fig. 4D).

\section{A PPI network links AL proteins to plant immunity}

As expected from their similar subcellular distribution, most proteins of this core set of nucleus-localized 


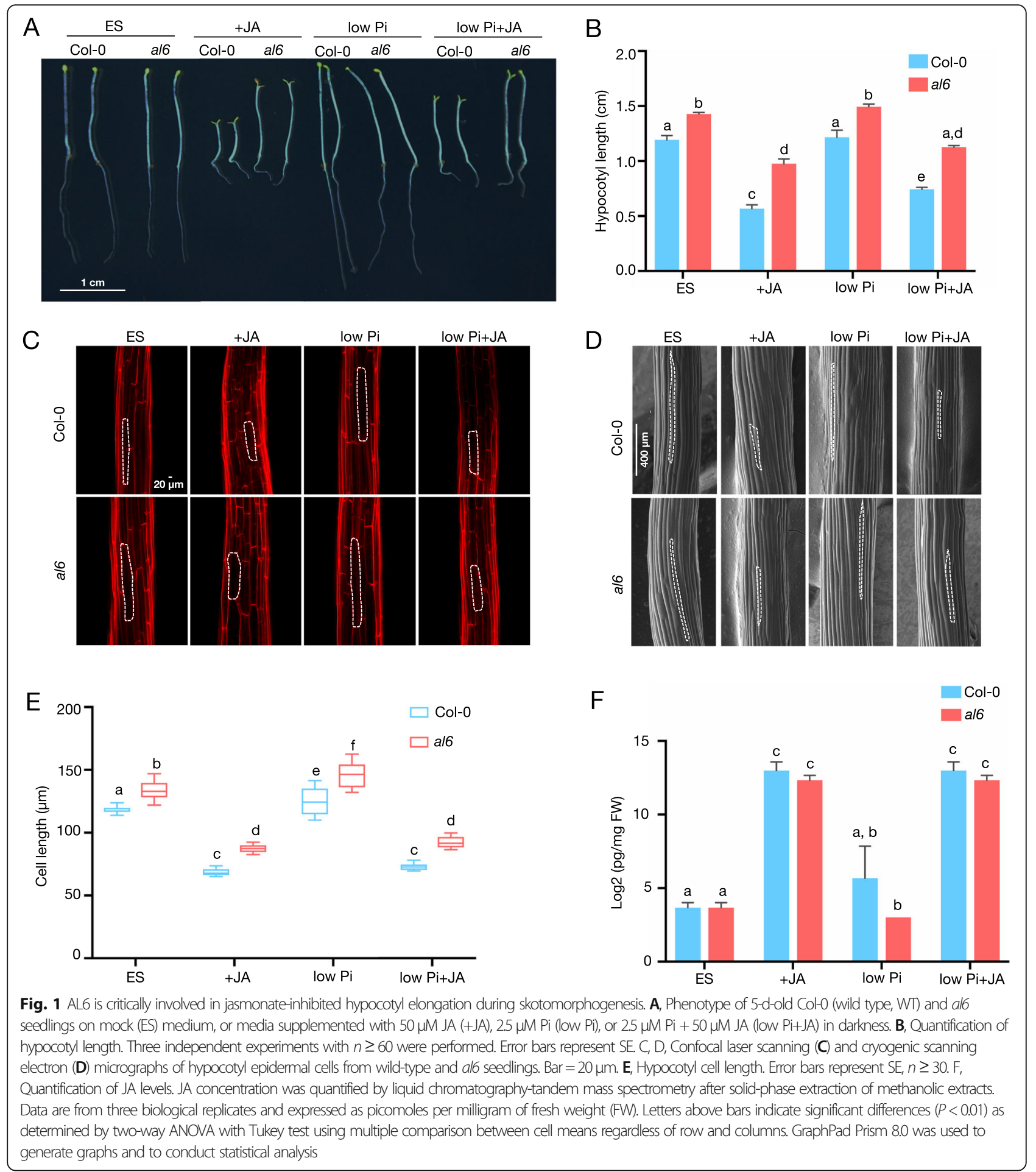

proteins have multiple predicted or validated proteinprotein interactions (PPIs), including AL2, AL3, AL6, and AL7 (Fig. 5). A PPI network considering the closest partners of the AL proteins revealed a central position of CELL DEVISION CYCLE 5 (CDC5), a MYB3R- and R2R3-type transcription factor that was shown to control growth and miRNA biogenesis [35, 51]. Together with MODIFIER OF SNC1,4 (MOS4) and the nuclear WD40 protein PLEIOTROPIC REGULATORY LOCUS 1 (PRL1), CDC5 forms the MOS4-Associated Complex (MAC) that confers innate immunity [26, 34, 50]. LHP1INTERACTING FACTOR 2 (LIF2), another MOS4interacting protein, also functions in plant innate immunity [23]. Notably, LIF2 was shown to be recruited 


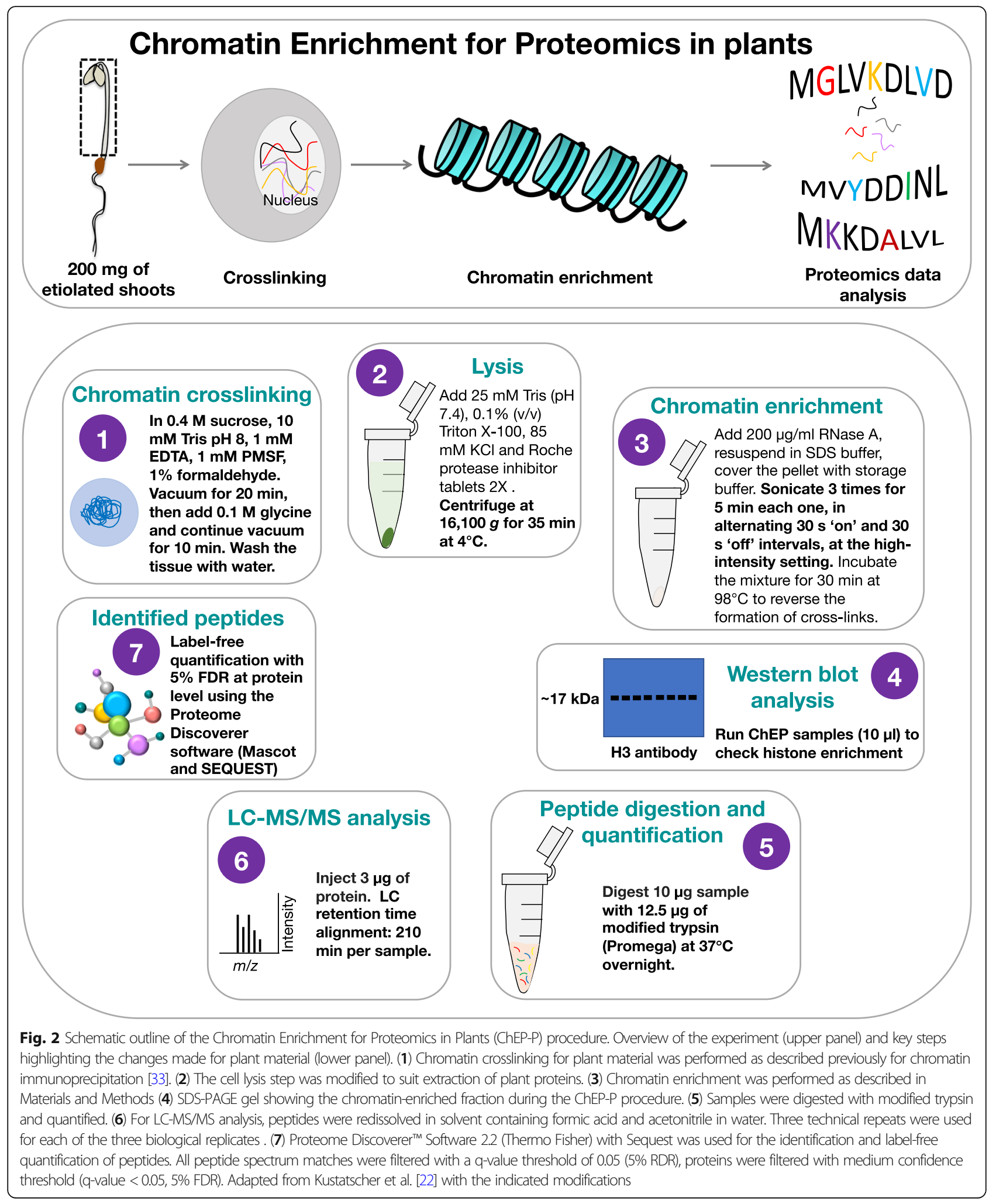

to chromatin upon JA treatment to regulate the transcription of JA-responsive genes [32]. Moreover, the transcriptome of lif2 mutants is enriched in the category 'JA-mediated signaling pathway' [23], underscoring the association of this protein to the response to JA. Conspicuously, LIF2 was found to more abundant in regions enriched in H3K4me3 [32]. Another LHP1-interacting factor, CYCLOPHILIN 71 (CYP71), is involved in 


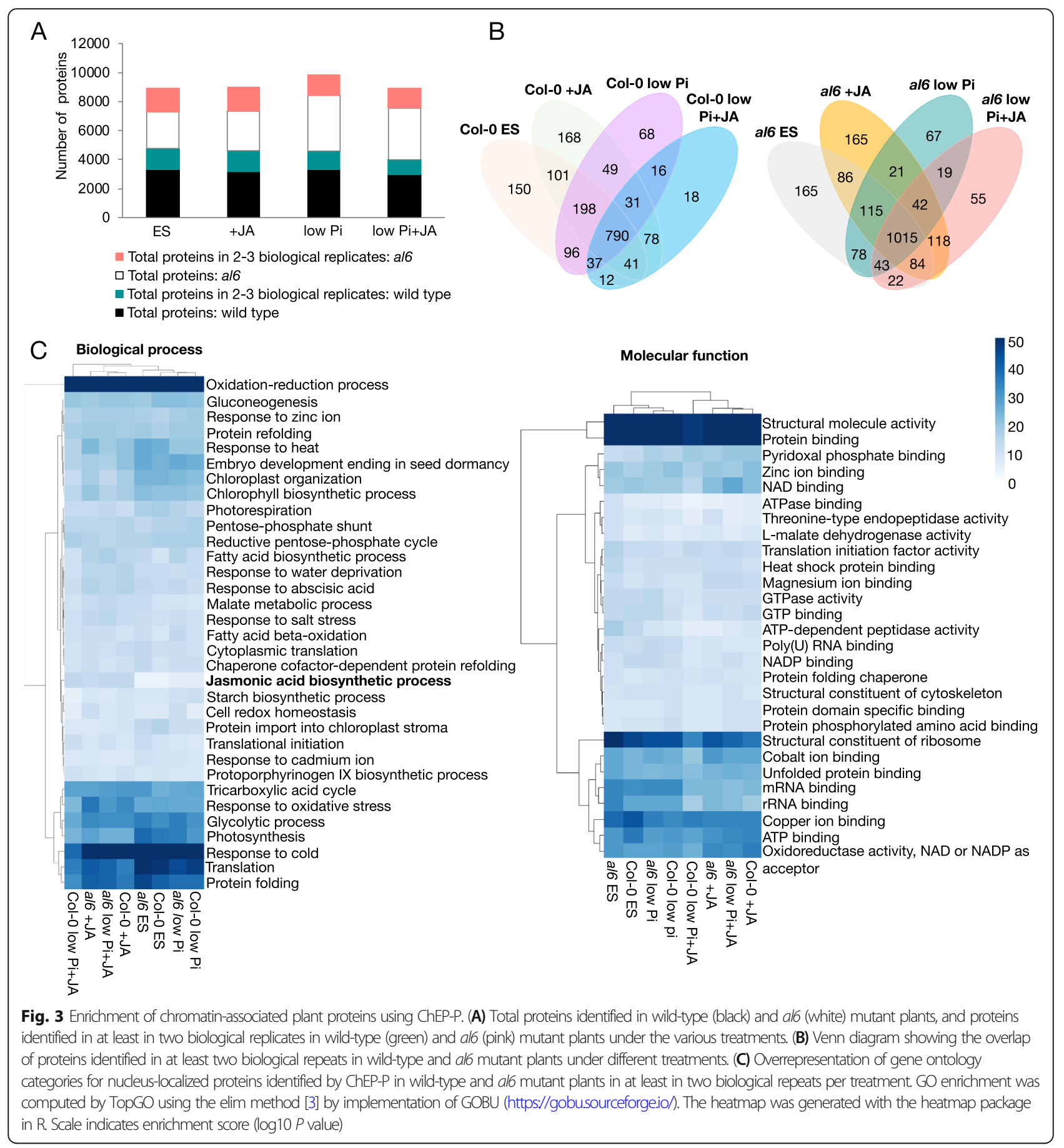

chromatin assembly and histone modifications [25]. Further, several proteins involved in nucleosome assembly and organization (NRP2, MSI1, NAP1.2, NAP1.2, NAP1.3, NFA6, and CHR11), histone acetylation (FVE, HDC1, HD1, HD2B, and HD2C), and components of the transcriptional machinery (NRPB1, NRPB2 and NRPB3) are part of this core network. ALFIN-LIKE proteins also have predicted interactions with TPL, a component of the JA repressor complex.
Label-free quantification reveals differences in chromatin dynamics between al6 and the wild type

Label-free quantification was employed to identify proteins that differentially accumulate among the treatments or between the genotypes under study. Only a relatively small subset of chromatin-associated proteins was responsive to JA (Supplementary Dataset S2). Of note, in both genotypes the histone variant HTA5 was upregulated in response to JA, but downregulated in low 


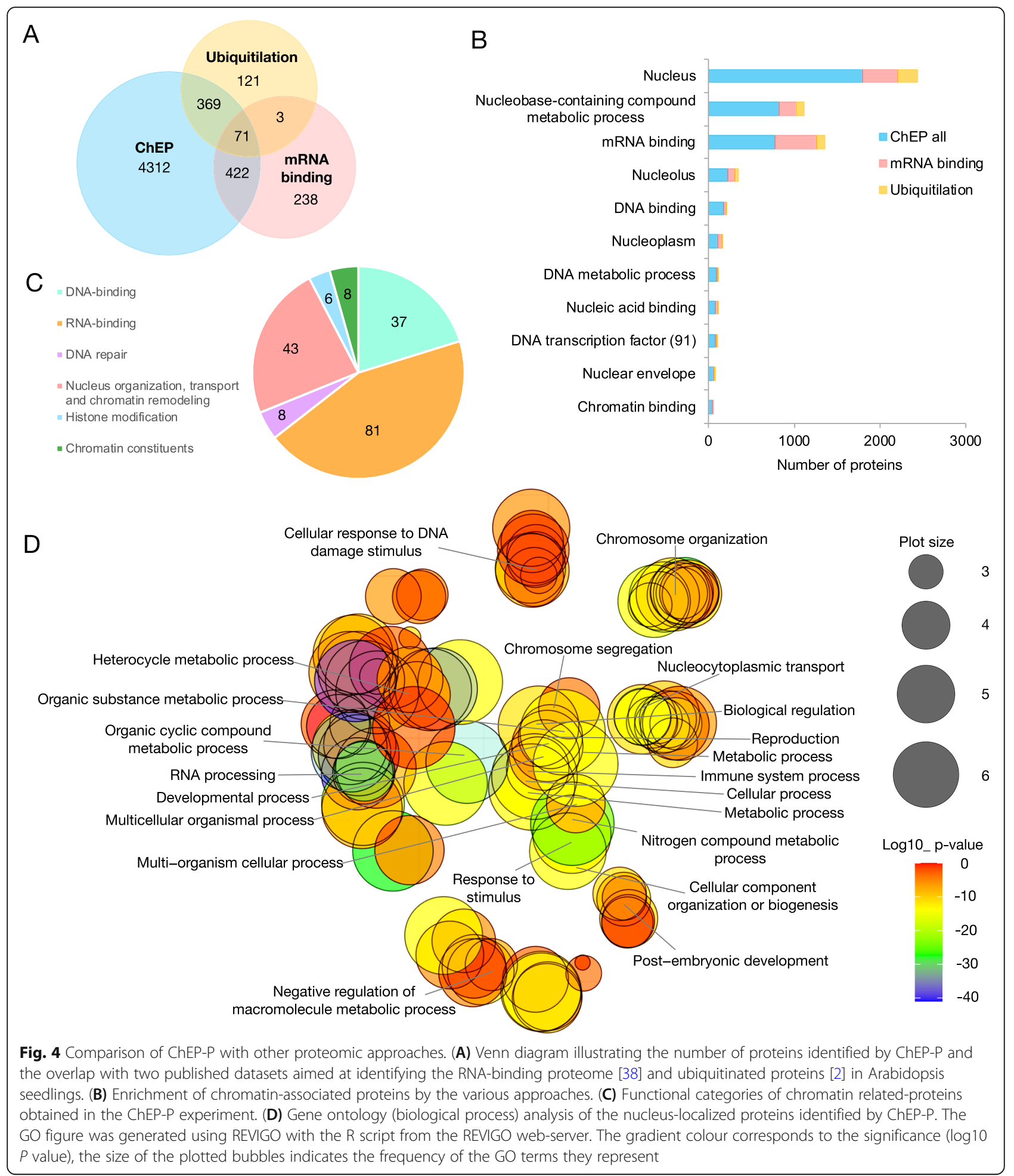

$\mathrm{Pi}$ and low $\mathrm{Pi}+\mathrm{JA}$. In wild-type plants, the abundance of RNA-BINDING PROTEIN 45A decreased under all experimental conditions, but the protein was not differentially expressed in al6 seedlings.

In wild-type plants, a subset of 89 proteins was responsive to low $\mathrm{Pi}$ and accumulated differentially between treated and control plants (Supplementary Dataset S2). Mutant plants responded to low Pi treatment with the differential expression of a markedly larger subset (140 proteins) of differentially expressed proteins (DEPs); only 35 DEPs were common in the data sets of both genotypes, including HTA5, HTA3, and 
Table 1 Chromatin-associated proteins identified by ChEP

\begin{tabular}{|c|c|c|c|c|}
\hline Locus/isoform & Name & Function & $\begin{array}{l}\text { Unique } \\
\text { peptides }\end{array}$ & Genotype \\
\hline \multicolumn{5}{|l|}{ DNA binding } \\
\hline At4g21710.1 & NRPB2 & DNA-templated transcription & 6 & WT; al6 \\
\hline At4g09000.2 & GRF1 & Regulation of transcription & 13 & WT; al6 \\
\hline At1g14410.1 & WHY1 & Regulation of transcription & 5 & WT; al6 \\
\hline At2g02740.1 & WHY3 & Regulation of transcription & 8 & WT; al6 \\
\hline At4g24800.1 & MRF3 & Regulation of transcription & 13 & WT; al6 \\
\hline At1g77180.1 & SKIP & Regulation of transcription & 3 & WT; al6 \\
\hline At5g65430.3 & GRF8 & Regulation of transcription & 7 & WT; al6 \\
\hline At1g22300.1 & GRF10 & Regulation of transcription & 15 & WT; al6 \\
\hline At1g09770.1 & CDC5 & Regulation of transcription & 8 & WT; al6 \\
\hline At5g63190.1 & MRF1 & Regulation of transcription & 6 & WT; al6 \\
\hline At5g38480.1 & GRF3 & Regulation of transcription & 14 & $W T ;$ al6 \\
\hline At5g65410.1 & ZHD1 & Regulation of gene expression & 4 & WT; al6 \\
\hline At1g15750.1 & TPL & Regulation of transcription & 7 & WT; al6 \\
\hline At5g04430.2 & BTR1 & Regulation of transcription & 16 & WT; al6 \\
\hline At2g32080.1 & PUR-ALPHA-1 & Regulation of transcription & 3 & WT; al6 \\
\hline At2g45640.1 & SAP18 & Regulation of transcription & 4 & WT; al6 \\
\hline At2g42560.1 & LEA25 & Unknown function & 7 & $a l 6$ \\
\hline AT3G58680.1 & MBF1b & Transcriptional coactivator & 4 & $a l 6$ \\
\hline At3g05060.1 & SAR DNA-binding protein & Box C/D RNP complex & 12 & WT; al6 \\
\hline At1g76010.1 & ALBA1 & Chromatin structure & 9 & WT; al6 \\
\hline At1g20220.1 & ALBA2 & Chromatin structure & 5 & WT; al6 \\
\hline At2g32080.1 & PUR ALPHA-1 & DNA replication & 3 & WT; al6 \\
\hline At1g48610.1 & AT-hook motif & DNA binding & 11 & WT; al6 \\
\hline At3g42170.1 & DAYSLEEPER & Transposase-like & 8 & WT; al6 \\
\hline At3g 10690.1 & GYRA & DNA topological change & 12 & WT; al6 \\
\hline At5g04130.1 & GYRB2 & DNA topological change & 7 & WT \\
\hline At4g25210.1 & DNA-binding storekeeper protein-related & Mediator complex & 2 & WT; al6 \\
\hline At4g39680.1 & SAP domain-containing protein & Nucleic acid binding (nucleus) & 18 & WT; al6 \\
\hline At4g36020.1 & CSP1 & DNA duplex unwinding & 7 & WT; al6 \\
\hline At4g26110.1 & NAP1;1 & DNA repair & 8 & $W T ;$ al6 \\
\hline At5g10010.1 & HIT4 & Negative regulation of gene silencing & 7 & WT; al6 \\
\hline \multicolumn{5}{|l|}{ RNA binding } \\
\hline At3g49601.1 & pre-mRNA-splicing factor & mRNA splicing & 5 & WT; al6 \\
\hline At2g 18510.1 & JANUS & mRNA splicing & 3 & WT \\
\hline At2g37340.1 & RSZ33 & mRNA splicing & 4 & WT \\
\hline At3g55460.1 & SCL30 & mRNA splicing & 6 & WT; al6 \\
\hline At3g55220.1 & SAP130B & mRNA splicing & 9 & WT; al6 \\
\hline At1g09760.1 & $U 2 A^{\prime}$ & mRNA splicing & 4 & WT; al6 \\
\hline At3g61240.1 & $\mathrm{RH} 12$ & mRNA binding (nucleus) & 2 & WT; al6 \\
\hline At2g14880.1 & SWIB2 & $\begin{array}{l}\text { Regulation of transcription by RNA } \\
\text { polymerase II }\end{array}$ & 5 & WT; al6 \\
\hline At4g17520.1 & HLN & mRNA binding (nucleus) & 12 & WT; al6 \\
\hline
\end{tabular}


Table 1 Chromatin-associated proteins identified by ChEP (Continued)

\begin{tabular}{|c|c|c|c|c|}
\hline Locus/isoform & Name & Function & $\begin{array}{l}\text { Unique } \\
\text { peptides }\end{array}$ & Genotype \\
\hline At5g39570.1 & PLDRP1 & mRNA binding (nucleus) & 11 & WT; al6 \\
\hline At4g34110.1 & PAB2 & mRNA binding (nucleus) & 15 & WT; al6 \\
\hline At2g23350.1 & PAB4 & mRNA binding (nucleus) & 17 & WT; al6 \\
\hline At5g47210.1 & Hyaluronan & mRNA binding (nucleus) & 18 & WT; al6 \\
\hline At1g51510.1 & Y14 & mRNA binding (nucleus) & 3 & WT; al6 \\
\hline At5g42820.2 & U2AF35B & mRNA splicing & 3 & WT; al6 \\
\hline At1g02140.1 & HAP1 & mRNA splicing & 3 & WT; al6 \\
\hline At3g49430.1 & SRP34A & mRNA splicing & 6 & WT; al6 \\
\hline At1g49760.1 & PAB8 & mRNA binding (nucleus) & 13 & WT; al6 \\
\hline At1g04080.3 & PRP39 & mRNA splicing & 10 & WT; al6 \\
\hline At5g04280.1 & RZ1C & mRNA splicing & 7 & WT; al6 \\
\hline At3g13570.1 & SLC30A & mRNA splicing & 4 & WT; al6 \\
\hline At3g26560.1 & ATP-dependent RNA helicase & mRNA splicing & 2 & WT \\
\hline At2g33340.1 & MAC3B & mRNA splicing & 12 & WT; al6 \\
\hline At1g80070.1 & SUS2 & mRNA splicing & 22 & WT; al6 \\
\hline At4g31580.1 & RSZ22 & mRNA splicing & 7 & WT; al6 \\
\hline At4g39260.1 & CCR1 & mRNA splicing & 11 & WT; al6 \\
\hline At2g24590.1 & RSZ22A & mRNA splicing & 3 & $a l 6$ \\
\hline At1g16610.3 & SR45 & mRNA splicing & 3 & WT; al6 \\
\hline At1g 14650.1 & SWAP & mRNA splicing & 4 & WT; al6 \\
\hline At2g 13540.1 & $\mathrm{ABH} 1$ & mRNA splicing & 4 & WT; al6 \\
\hline At5g64270.1 & Splicing factor & mRNA splicing & 11 & WT; al6 \\
\hline At2g38770.1 & MAC7 & mRNA splicing & 7 & WT; al6 \\
\hline At1g20960.1 & BRR2 & mRNA splicing & 34 & WT; al6 \\
\hline At5g41770.1 & Crooked neck protein & mRNA splicing & 3 & WT; al6 \\
\hline At5g52040.2 & RS41 & mRNA splicing & 6 & WT; al6 \\
\hline At5g54900.1 & RBP45A & mRNA binding (nucleus) & 8 & WT; al6 \\
\hline At1g11650.2 & RBP45B & mRNA binding (nucleus) & 5 & WT \\
\hline At2g42520.1 & $\mathrm{RH} 37$ & mRNA binding (nucleus) & 6 & WT; al6 \\
\hline At3g58510.1 & $\mathrm{RH} 11$ & mRNA binding (nucleus) & 9 & WT; al6 \\
\hline At1g29250.1 & ALBA1 & mRNA-binding (nucleus) & 5 & WT; al6 \\
\hline At2g33410.1 & RBGD2 & mRNA-binding (nucleus) & 4 & WT; al6 \\
\hline At4g00830.1 & LIF2 & mRNA-binding (nucleus) & 5 & WT; al6 \\
\hline At5g07350.2 & TSN1 & mRNA binding (nucleus) & 25 & WT; al6 \\
\hline At1g13190.1 & RNA-binding (RRM/RBD/RNP motifs) family protein & mRNA binding (nucleus) & 2 & WT; al6 \\
\hline At5g61780.1 & TSN2 & mRNA binding (nucleus) & 22 & WT; al6 \\
\hline At3g04610.1 & FLK & $\begin{array}{l}\text { mRNA binding, regulation of gene } \\
\text { expression }\end{array}$ & 4 & WT; al6 \\
\hline At1g48920.1 & PARL1 & rRNA processing & 24 & WT; al6 \\
\hline At5g52470.1 & FIB1 & RNA methylation & 10 & WT; al6 \\
\hline At2g21660.1 & CCR2 & mRNA export from the nucleus & 10 & WT; al6 \\
\hline At3g 10650.1 & NUP1 & mRNA export from the nucleus & 6 & WT; al6 \\
\hline At2g05120.1 & NUP133 & mRNA export from the nucleus & 4 & WT; al6 \\
\hline At1g14850.1 & NUP155 & Nucleoporin & 12 & WT; al6 \\
\hline
\end{tabular}


Table 1 Chromatin-associated proteins identified by ChEP (Continued)

\begin{tabular}{|c|c|c|c|c|}
\hline Locus/isoform & Name & Function & $\begin{array}{l}\text { Unique } \\
\text { peptides }\end{array}$ & Genotype \\
\hline At1g69250.1 & NTF2 & mRNA export from the nucleus & 4 & al6 \\
\hline At2g16950.1 & TRN1 & Nuclear import & 4 & al6 \\
\hline At3g06720.1 & IMPA-1 & Nuclear import & 3 & WT; al6 \\
\hline At4g16143.1 & IMPA-2 & Nuclear import & 9 & WT; al6 \\
\hline At1g09270.1 & IMPA-4 & Nuclear import & 5 & WT; al6 \\
\hline At1g75660.1 & XRN3 & miRNA catabolic process & 4 & WT; al6 \\
\hline At1g26110.1 & DCP5 & mRNA decapping & 3 & al6 \\
\hline AT5G25757.1 & RNA polymerase I-associated factor PAF67 & RNA polymerase I-associated & 9 & WT; al6 \\
\hline At2g06990.1 & HEN2 & mRNA processing & 3 & WT; al6 \\
\hline At3g03920.1 & H/ACA ribonucleoprotein complex & $\begin{array}{l}\text { snoRNA guided rRNA pseudouridine } \\
\text { synthesis }\end{array}$ & 4 & alo \\
\hline At3g57150.1 & NAP57 & mRNA pseudouridine synthesis & 12 & WT; al6 \\
\hline \multicolumn{5}{|l|}{ DNA repair } \\
\hline At3g02540.1 & RAD23C & DNA repair & 3 & al6 \\
\hline At5g38470.1 & RAD23D & DNA repair & 3 & WT; al6 \\
\hline At4g31880.1 & PDS5C & DNA repair & 15 & WT; al6 \\
\hline At5g55660.1 & DEK domain-containing chromatin associated protein & DNA repair & 10 & WT; al6 \\
\hline At2g36060.2 & MMZ3 & DNA repair & 4 & WT; al6 \\
\hline At2g29570.1 & PCNA2 & DNA repair & 2 & WT; al6 \\
\hline At5g47690.1 & PDS5A & DNA repair & 11 & WT; al6 \\
\hline At3g04880.1 & DRT102 & DNA repair & 5 & WT; al6 \\
\hline \multicolumn{5}{|c|}{ Nucleus organization, transport, and chromatin remodeling } \\
\hline At1g74560.3 & NRP1 & Nucleosome assembly & 1 & WT; al6 \\
\hline At3g18035.1 & HON4 & Nucleosome assembly & 9 & WT;al6 \\
\hline At2g19480.1 & NAP1;2 & Nucleosome assembly & 11 & WT; al6 \\
\hline At5g56950.1 & NAP1;3 & Nucleosome assembly & 3 & WT; al6 \\
\hline At1g20693.1 & HMGB2 & Chromatin assembly/disassembly & 2 & WT; al6 \\
\hline At1g48620.1 & HON5 & Nucleosome assembly & 7 & WT; al6 \\
\hline At5g58230.1 & MSI1 & Chromatin assembly & 3 & WT; al6 \\
\hline At1g27970.2 & NTF2B & Nucleocytoplasmatic transport & 5 & $W T ;$ al6 \\
\hline At1g65440.1 & GTB1 & $\begin{array}{l}\text { Regulation of transcription; chromatin } \\
\text { assembly }\end{array}$ & 5 & WT; al6 \\
\hline At4g26630.1 & DEK3 & Chromatin remodeling & 10 & WT; al6 \\
\hline At3g06400.3 & CHR11 & Chromatin remodeling & 2 & WT; al6 \\
\hline At5g67630.1 & ISE4 & Chromatin remodeling & 9 & WT; al6 \\
\hline At1g67230.1 & LINC1 & Nuclear structure & 18 & WT; al6 \\
\hline At4g31430.2 & KAKU4 & Nuclear membrane organization & 5 & WT; al6 \\
\hline At5g55190.1 & RAN3 & Nuclear transport of proteins & 8 & WT; al6 \\
\hline At2g47970.1 & NPL4 & Nuclear pore localization protein & 5 & WT; al6 \\
\hline At4g15900.1 & PRL1 & Protein binding (nucleus) & 6 & $a l 6$ \\
\hline At5g 17020.1 & XPO1 & Nuclear export & 7 & WT; al6 \\
\hline At3g44110.1 & ATJ & DNA replication & 4 & WT; al6 \\
\hline At2g46520.1 & XPO2 & Protein export from nucleus & 5 & WT; al6 \\
\hline
\end{tabular}


Table 1 Chromatin-associated proteins identified by ChEP (Continued)

\begin{tabular}{|c|c|c|c|c|}
\hline Locus/isoform & Name & Function & $\begin{array}{l}\text { Unique } \\
\text { peptides }\end{array}$ & Genotype \\
\hline At1g79280.2 & NUA & Nuclear transport of proteins & 22 & WT; al6 \\
\hline At5g43960.1 & Nuclear transport factor 2 (NTF2) family protein & Nuclear transport of proteins & 6 & WT; al6 \\
\hline At1g56110.1 & NOP56 & snoRNA binding & 11 & WT; al6 \\
\hline At1g14900.1 & HMGA & Chromosome condensation & 3 & WT; al6 \\
\hline At5g20200.1 & Nucleoporin-like protein & $\begin{array}{l}\text { Nuclear membrane organization, DNA } \\
\text { replication }\end{array}$ & 6 & WT; al6 \\
\hline At5g60980.2 & NTF2 & Nuclear transport & 4 & WT; al6 \\
\hline At3g51050.1 & NERD1 & Unidimensional cell growth & 2 & WT; al6 \\
\hline At1g19880.1 & $\mathrm{RCC1}$ & Chromosome condensation & 3 & WT; al6 \\
\hline At5g11170.1 & UAP56A & RNA-directed DNA methylation & 19 & WT; al6 \\
\hline At3g15670.1 & LEA76 & Nuclear protein & 9 & WT; al6 \\
\hline At1g15340.1 & MBD10 & Methyl-CpG-binding domain & 7 & WT; al6 \\
\hline At1g61000.1 & NUF2 & Kinetochore organization & 1 & WT; al6 \\
\hline At5g63860.1 & UVR8 & Chromatin binding & 7 & al6 \\
\hline At1g47200.1 & WPP2 & Mitosis & 6 & WT; al6 \\
\hline \multicolumn{5}{|c|}{ Histone modification } \\
\hline At5g03740.1 & HDT3 & Histone deacetylation & 7 & WT; al6 \\
\hline At2g19520.1 & NFC4 & Histone modification & 8 & WT; al6 \\
\hline At5g22650.1 & HAD4 & Histone deacetylation & 5 & WT; al6 \\
\hline At5g08450.1 & $\mathrm{HDC1}$ & Histone deacetylation & 4 & WT; al6 \\
\hline At4g38130.1 & HD1 & Histone deacetylation & 2 & $a l 6$ \\
\hline At5g45690.1 & Histone acetyltransferase & Histone acetylation & 13 & WT; al6 \\
\hline \multicolumn{5}{|c|}{ Chromatin constituents } \\
\hline At1g08880.1 & HTA5 & Histone superfamily protein & 1 & WT; al6 \\
\hline At5g65360.1 & HRT1 & Histone superfamily protein & 4 & WT; al6 \\
\hline At2g30620.1 & $\mathrm{H} 1.2$ & Histone superfamily protein & 8 & WT; al6 \\
\hline At3g46030.1 & HTB11 & Histone superfamily protein & 1 & WT; al6 \\
\hline At1g01370.1 & HTR12 & Histone superfamily protein & 2 & $a \mid 6$ \\
\hline At5g59970.1 & Histone superfamily protein & Histone superfamily protein & 14 & WT; al6 \\
\hline \multicolumn{5}{|l|}{ Low Pi only } \\
\hline At1g61730.1 & $\begin{array}{l}\text { DNA-binding storekeeper protein-related transcriptional } \\
\text { regulator }\end{array}$ & Regulation of transcription & 6 & $a l 6$ \\
\hline At3g01540.2 & $\mathrm{RH} 14^{1}$ & rRNA processing & 9 & alo \\
\hline At5g02530.1 & ALY2 & mRNA binding (nucleus) & 3 & $a l 6$ \\
\hline At2g20490.1 & EDA27 & rRNA pseudouridine synthesis & 3 & WT \\
\hline At1g80930.1 & $\begin{array}{l}\text { MIF4G domain-containing protein / MA3 domain- } \\
\text { containing protein }\end{array}$ & mRNA splicing & 1 & $a l 6$ \\
\hline At4g35800.1 & NRBP $1^{1}$ & RNA polymerase ॥ & 8 & WT; al6 \\
\hline At3g62310.1 & DEAH RNA helicase homolog PRP43 & mRNA binding (nucleus) & 2 & $a l 6$ \\
\hline At3g50670.1 & U1SNRNP ${ }^{1}$ & mRNA splicing & 3 & WT; al6 \\
\hline At1g65090.2 & Nucleolin $^{2}$ & Nucleolar protein & 3 & $a l 6$ \\
\hline At1g06760.1 & HON $1^{1}$ & Nucleosome positioning & 3 & WT; al6 \\
\hline At3g11200.1 & $\mathrm{AL} 2^{1}$ & Histone binding & 2 & WT \\
\hline At1g14510.1 & $\mathrm{AL} 7^{1}$ & Histone binding & 1 & WT; al6 \\
\hline
\end{tabular}


Table 1 Chromatin-associated proteins identified by ChEP (Continued)

\begin{tabular}{|c|c|c|c|c|}
\hline Locus/isoform & Name & Function & $\begin{array}{l}\text { Unique } \\
\text { peptides }\end{array}$ & Genotype \\
\hline At3g18165.1 & $\mathrm{MOS}_{4}^{2}$ & Protein binding (nucleus) & 5 & WT; al6 \\
\hline At4g05420.1 & DDB1A & Regulation of transcription & 2 & WT; al6 \\
\hline At5g27670.1 & $\mathrm{HTA} 7^{2}$ & Histone H2A.5 protein & 2 & WT; al6 \\
\hline \multicolumn{5}{|l|}{$+J A$ only } \\
\hline At3g44600.1 & CYP71 & Chromatin binding & 5 & WT \\
\hline At3g50670.1 & U1SNRNP ${ }^{1}$ & mRNA splicing & 3 & WT; al6 \\
\hline At4g32720.1 & $\mathrm{LA} 1$ & rRNA processing & 2 & al6 \\
\hline At4g35800.1 & NRBP $1^{1}$ & RNA polymerase ॥ & 7 & $a / 6$ \\
\hline At3g01540.2 & $\mathrm{RH} 14^{1}$ & rRNA processing & 4 & WT \\
\hline At5g53620.1 & MNC6.16 & RNA polymerase II degradation & 2 & al6 \\
\hline At4g 24270.2 & EMB140 & RNA processing & 3 & al6 \\
\hline At1g33240.1 & GTL1 & Negative regulation of transcription & 3 & al6 \\
\hline At5g28040.1 & VFP4 & Regulation of transcription & 1 & al6 \\
\hline At3g50370.1 & Hypothetical protein & mRNA binding (nucleus) & & \\
\hline At2g27100.1 & $\mathrm{SE}^{3}$ & mRNA splicing & 8 & WT; al6 \\
\hline At1g06760.1 & $\mathrm{HON} 1^{1}$ & Nucleosome positioning & 3 & al6 \\
\hline At3g 11200.1 & $\mathrm{AL}^{1}$ & Histone binding & 3 & WT; al6 \\
\hline At3g42790.1 & AL3 & Histone binding & 2 & al6 \\
\hline At1g14510.1 & $A L 7^{1}$ & Histone binding & 1 & WT; al6 \\
\hline At4g27000.1 & RBP45C & mRNA binding (nucleus) & 4 & WT \\
\hline At1g23860.1 & RSZ21 & mRNA splicing & 1 & al6 \\
\hline At1g65010.1 & Microtubule-associated protein & Reciprocal meiotic recombination & 10 & al6 \\
\hline At5g37720.1 & ALY4 & mRNA export from the nucleus & 5 & al6 \\
\hline At2g 15430.1 & NRPB3 & RNA polymerase II, IV and V & 2 & al6 \\
\hline At4g36690.1 & U2AF65A & mRNA splicing & 5 & $a / 6$ \\
\hline \multicolumn{5}{|l|}{ Low Pi $+J A$ only } \\
\hline At2g27100.1 & $\mathrm{SE}^{3}$ & mRNA splicing & 8 & al6 \\
\hline At5g27670.1 & $\mathrm{HTA} 7^{2}$ & Histone $\mathrm{H} 2 \mathrm{~A}$ protein & 2 & al6 \\
\hline At1g65090.2 & Nucleolin ${ }^{2}$ & Nucleolar protein & 3 & $a \mid 6$ \\
\hline At2g02470.1 & AL6 & Histone binding & 1 & al6 \\
\hline At2g41620.1 & Nucleoporin interacting component & mRNA export from the nucleus & 2 & al6 \\
\hline At3g 18165.1 & MOS4 ${ }^{2}$ & Protein binding (nucleus) & 5 & $a / 6$ \\
\hline At3g 11450.1 & ZRF1A & Chromatin silencing & 3 & al6 \\
\hline At1g18800.1 & NRP2 & Chromatin assembly & 1 & al6 \\
\hline At5g22880.1 & HTB2 & Histone family protein & 1 & WT;al6 \\
\hline
\end{tabular}

Proteins identified by ChEP-P in at least two replicates with predominant nuclear localization were considered. ${ }^{1}$ in low $\mathrm{Pi}+\mathrm{JA} ;{ }^{2}$ in low $\mathrm{Pi}$ and low $\mathrm{Pi}+\mathrm{JA} ;{ }^{3}$ in $+\mathrm{JA}$ and low $\mathrm{Pi}+\mathrm{JA} ; \mathrm{WT}$, wild type

AL7. The more pronounced Pi deficiency response of al6 mutant plants was also reflected by a more complex pattern of overrepresented GO categories (Fig. 6).

When plants were grown on low $\mathrm{Pi}+\mathrm{JA}$ media, in both genotypes the histones HTB2 and HTA3 showed increased abundance whereas HTB11 and HTA5 decreased in response to this treatment, pointing to alterations in chromatin organization under these conditions. In wild-type seedlings, low $\mathrm{Pi}+\mathrm{JA}$ treatment resulted in additive enrichment of GO categories observed upon either growth condition, a pattern which was not observed in mutant plants, in which the response to the combined treatment was rather similar to what was observed with JA alone. 


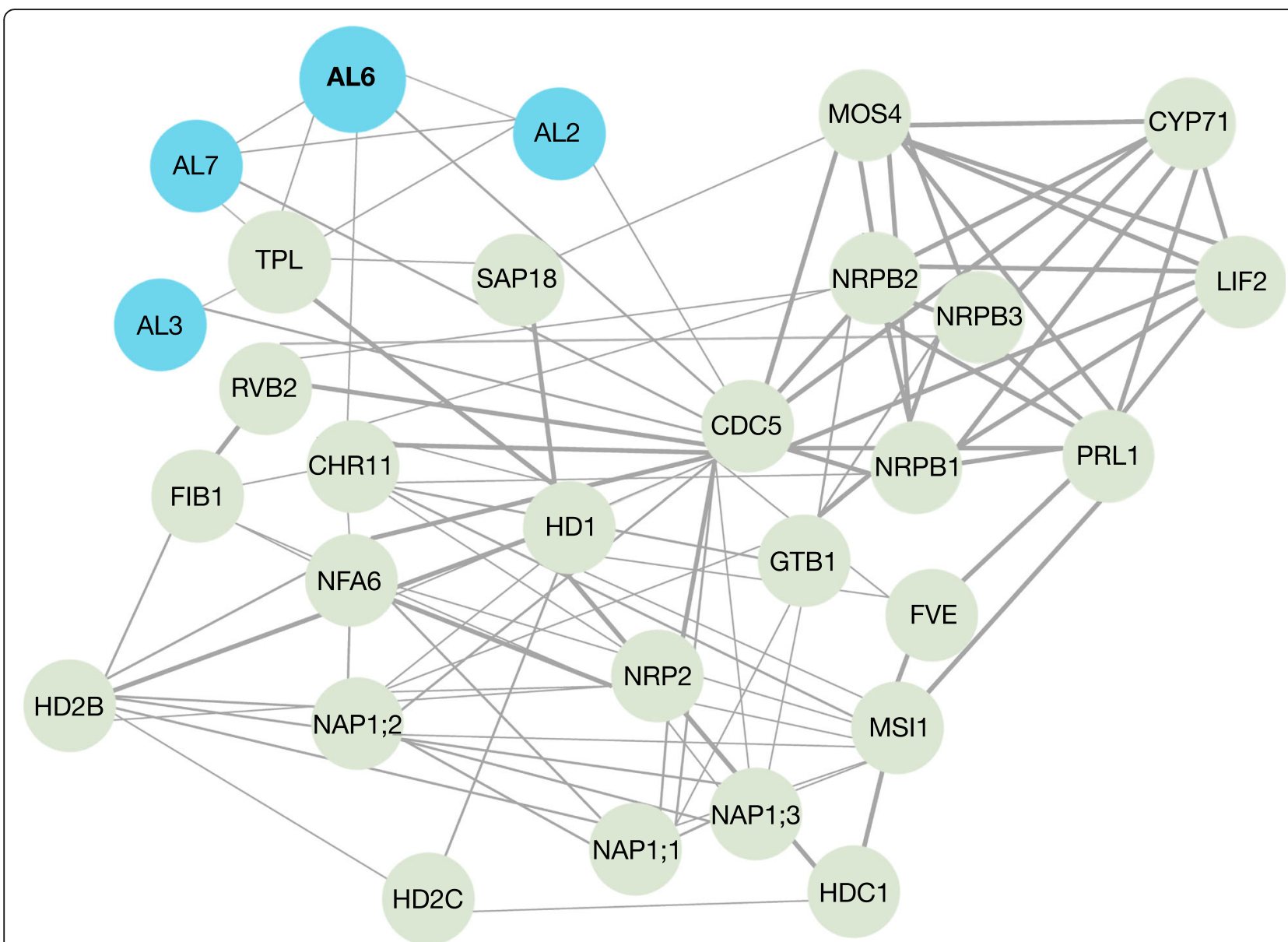

Fig. 5 Protein-protein interaction (PPI) network of chromatin-associated proteins identified with the ChEP-P. The search tool for retrieval of interacting genes (STRING) (https://string-db.org) was used to construct the PPI network. Only the closest partners of AL proteins are considered

Among the chromatin-associated proteins that were differentially expressed between the two genotypes, the expression of NAP1-RELATED PROTEIN 1 (NRP1) and the related NAP1;2 was highly upregulated in al6 relative to wild-type plants (Supplementary Dataset S3). NAP1 was shown to repress the SRW1 chromatinremodeling complex [46]. In agreement with such a role of NAP1, the SWR1 component CHROMATINREMODELING PROTEIN 11 (CHR11) showed a markedly decreased abundance in al6 mutant plants [29]. Noteworthily, several chromatin-related proteins were either not differentially expressed in response to the experimental treatments, anti-directionally regulated in al6 mutants relative to wild-type plants (e.g., HTA5, HTB11, H1.2, RBP45A), were solely regulated in al6 plants (e.g., CHR11, H2B, and HIGH MOBILITY GROUP), or were anti-directionally regulated in both genotypes (HTB11). Moreover, a suite of genes involved in the biosynthesis of or response to JA (CORI7, GSH1) and auxin biosynthesis (SUR1) were only differentially expressed in wildtype plants (Fig. 7).

\section{Discussion}

ChEP-P detects a comprehensive suite of chromatinassociated proteins

The identification of chromatin-associated proteins and changes in their relative abundance upon perception of internal or external cues allows insights into the complex interplay between DNA and regulatory proteins that orchestrate gene activity. Detection of lowly abundant proteins is, however, notoriously difficult which renders approaches aimed at providing a comprehensive inventory of chromatin-associated proteins difficult. Antibody-based methods such as ChIP or tandem affinity purification have been widely employed for mapping the interaction of trans-acting factors with regulatory DNA sequences. However, the requirement for protein-specific antibodies or tagged proteins limits this method to one or a few proteins that can be studied at the same time, restricting the utility of this approach when a more holistic view is desired. Chromatin enrichment coupled with tandem MSbased proteomics profiling allows for unbiased protein identification and is better suited than whole cell 


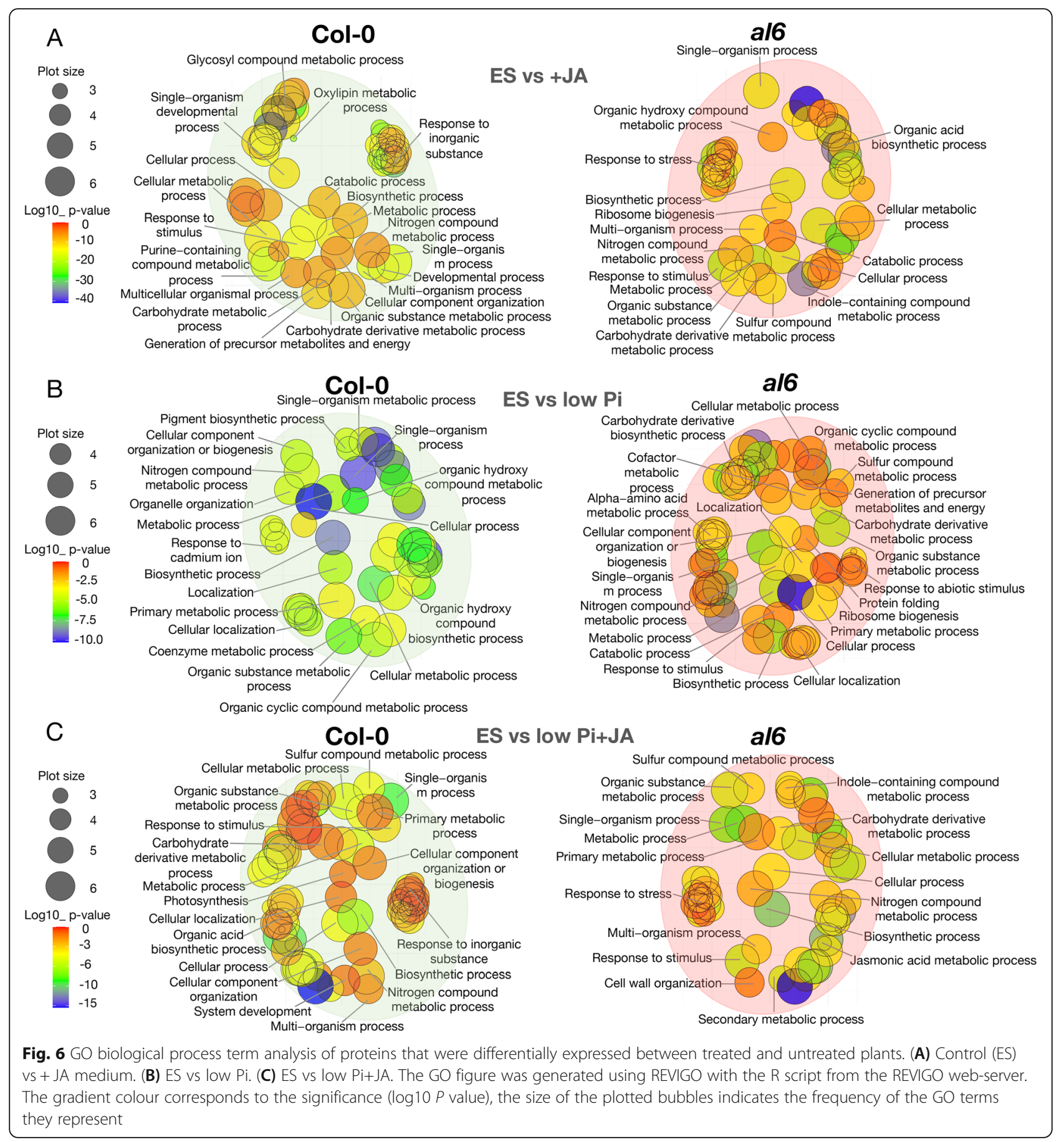

proteomics to detect lowly abundant chromatinassociated proteins. Moreover, due to the stringent washing buffer of formaldehyde-crosslinked DNA and the use of RNase A, ChEP provides a significant discrimination against highly abundant ribosomal and cytoplasmic proteins. Despite these obvious advantages, so far ChEP has not been successfully employed to study chromatinassociated proteins in plants. While it remains obscure why this is the case, it should be stated that modifications of each step of the ChEP procedure are required to adopt the method for plant materials (Fig. 2) which may have rendered approaches using a protocol developed for nonplant tissues inefficient.

While ChEP is based on a fast and economic protocol and does not require sophisticated instrumental setups other that MS, the charged nature of chromatin may cause a significant dilution of ChEP-derived protein profiles by proteins from other cell 


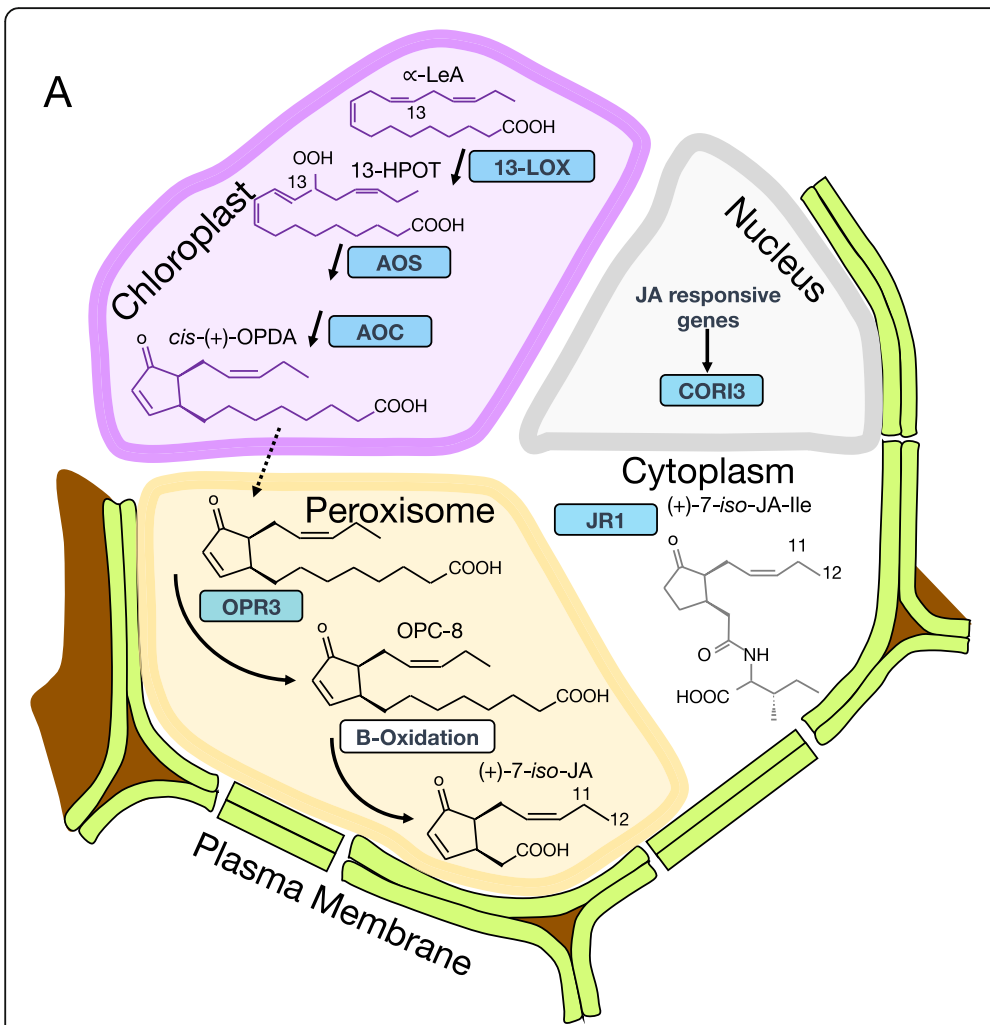

B

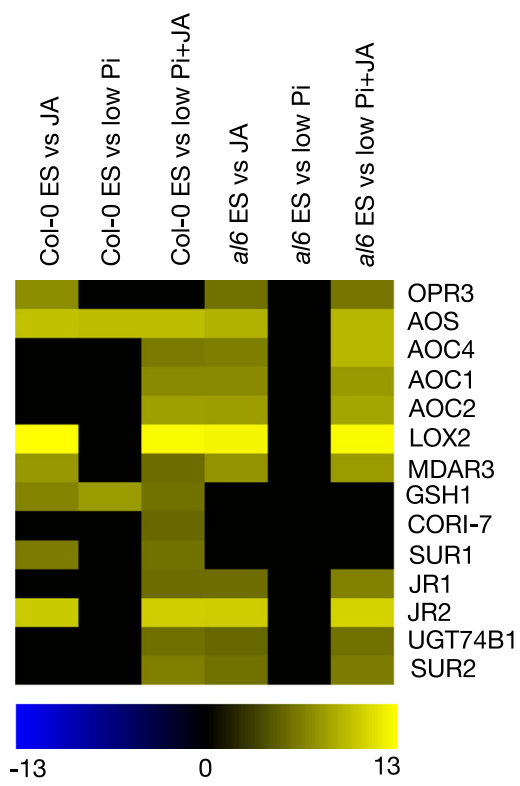

Fig. 7 Differentially expressed proteins involved in JA biosynthesis. (A) Role of differentially expressed proteins in JA biosynthesis. (B) Heatmap showing the expression pattern of JA-related proteins in wild-type and al6 mutant plants upon exposure to the experimental treatments. The heat map was constructed using normalized protein abundance of differential expressed proteins; zero values denote absence of the protein in the respective dataset

compartments [21]. This was also the case in the present study where contaminants also derived from chloroplasts. However, proteins of origins other than the nucleus may also transport biologically meaningful information, as they may not occur entirely at random [21], or may represent proteins that are transiently bound to chromatin. Moreover, enrichment for chromatin-associated proteins appears to depend on the material under study and the conditions of the experiment, yielding a different degree of enrichment [22].

\section{Altered chromatin dynamics could be causative for the low $\mathrm{Pi}$ and $\mathrm{JA}$ signalling phenotypes of al6}

The present study associates the histone reader AL6 with the response of etiolated seedlings to JA, resulting in the repression of skotomorphogenesis by inhibiting hypocotyl cell elongation. The exact molecular mechanism underlying the role of AL6 in the response to JA is presently unclear. Previously published results links AL to Polycomb Group (PcG) protein-mediated gene silencing. More specifically, it was demonstrated that AL6 and AL7 interact with the C-terminus of core components of PcG-Repressive Complex 1 (PRC1), triggering a switch from the active H3K4me3 mark to the repressive
H3K27me3 via recruitment of PRC2 [31]. It was further demonstrated that the H3K27me3 reader protein LIKEHETEROCHROMATIN PROTEIN 1 (LHP1), a component of PRC1, regulates the transcription of stressresponsive genes in concert with the heterogeneous nuclear ribonucleoprotein Q protein LIF2 [32]. Application of methyl jasmonate (MeJA) was found to recruit LIF2 to chromatin [32], suggesting a mechanistic link between PcG proteins and JA signalling. More recently, LHP1 was shown to interact with JAZ proteins to repress the transcription of JA-responsive genes by introducing repressive chromatin modifications [27], indicating a dynamic interplay of histone methylation and JA signalling. Conspicuously, LIF2 is closely co-expressed with AL6 (atted.jp and Supplementary Fig. S2), further supporting this scenario. Beside AL3 and CDC5 which are also in the PPI network, another protein involved in miRNA biogenesis, MOS2 [48], is part of the AL6 co-expression network, indicating a possible involvement of miRNAs in AL-mediated processes. Interestingly, MOS2 was associated with innate immunity in a forward genetic screen [52].

In the present study, an involvement of AL6 in dynamic changes at the chromatin level can be inferred from label- 
free quantification of proteins that accumulate differentially between the two genotypes. For example, the histone chaperons NUCLEOSOME ASSEMBLY PROTEIN 1;2 (NAP1;2) and NAP1-RELATED PROTEIN 1 (NRP1) were highly upregulated in al6 seedlings (Supplementary Dataset S3). NRP1 negatively regulates the deposition of the histone $\mathrm{H} 2 \mathrm{~A}$ variant H2A.Z in chromatin by repressing the SWR1 chromatinremodelling complex [46]. Notably, NAP1;2 was shown to be critical for the recalibration of Pi homeostasis in Arabidopsis, possibly by modulating H2A.Z deposition at the transcriptional start sites of Pi-responsive genes [16, 39]. The SWR1 component CHR11 was downregulated in al6 mutant plants. Thus, it may be speculated that H2A.Z deposition of a subset of genes may be compromised in al6 mutants, leading to a more pronounced response to Pi starvation as it was observed in mutants harbouring defects in the SWR1 subunit ACTIN-RELATED PROTEIN 6 (APR6), in which H2A.Z deposition is repressed [11, 39]. In fact, we previously found that, similar to al6, arp 6 mutants form very short root hairs upon $\mathrm{Pi}$ starvation, suggesting that compromised H2A.Z deposition is causative for the deregulated Pi starvation response in both mutants [41]. H2A.Z is colocalized with H3K4me3 and promotes formation of H3K27me3 [7], matching the pattern of the putative distribution and function of AL6.

\section{AL6 may participate in the repression of JA signalling}

Taken together, our data support a model in which AL6, and possibly other AL proteins, act as a component of the repressor complex in JA signalling, supporting the deposition of repressive histone modifications by recruiting PcG proteins (Fig. 8). This supposition is supported by the validated binding of AL6 to PRC1 components [31] and predicted interactions of AL proteins with JA signalling inhibitors such as TPL. The JA-insensitive phenotype of the al6 mutant appears, at first sight, counterintuitive if a role of AL6 in repressing JA responses is supposed. However, the available data suggest a more complex picture for the interplay of histone modifications and JA signalling. Loss of AL6 function appears to be associated with reduced $\mathrm{H} 2 \mathrm{~A} . \mathrm{Z}$ deposition, an assumption that is inferred from the differential accumulation of NAP1 and CHR11, the aggravated response of al6 Pi deficiency and the short root hair phenotype of al6 mutants under such conditions, which resemble mutants defective in H2A.Z deposition [8, 39, 41] Regions targeted by LIF2 and the PcG protein LHF1 were found to be enriched in H2A.Z [32], a condition which is not met in the absence of AL6 and may lead to a delayed or compromised response to JA. Strikingly, we found that reduced HDA19 transcript levels led to a phenotype that is similar to al6 under the present conditions and treatments (Supplementary Fig. S3), supporting this conclusion. Similar to what is assumed for AL6, HDA19 and HDA6 were shown repress the transcription of JA-responsive genes as part of a co-repressor complex and required for the repression of photomorphogenesis $[47,55]$. Noteworthily, H3K4 trimethylation of a subset of stress-responsive genes was impaired in the HDA6 mutant axe1-5, suggesting that histone acetylation is linked to H3K4 methylation [49]. Similar to al6, mutants harbouring defects in HDA6 and HDA19 form short root hairs under low Pi conditions and show a compromised Pi starvation response [9], suggesting that histone acetylation is critical for both the adaptation to low Pi availability and proper JA signalling. Interestingly, Pi deficiency was shown to trigger JA biosynthesis and signalling [19], linking the two responses at a biochemical level. However, in contrast to what has observed for roots, in etiolated seedlings low Pi availability does not induce JA biosynthesis and rather repress the response to JA.

\section{Conclusions}

In conclusion, we show here that the histone reader AL6 is involved in the response to JA during skotomorphogenesis, possibly mediated by a PRC1/2-mediated switch in H3K4me3 to H3K27me3 and altered deposition of the histone variant H2A.Z. The pleiotropic phenotype of al6 mutants supports a critical role of AL6 in the interpretation of environmental information and highlights its at least partly non-redundant role within members of the enigmatic $\mathrm{AL}$ protein family. We further show that processes as diverse as root responses to Pi starvation and hypocotyl elongation of etiolated seedlings converge at critical nodes at the chromatin level that modulate the phenotypic readout in a vast array of environmental and developmental responses. While the exact molecular mechanism by which AL6 mediates the response to JA requires further experimentation, it can be stated that ChEP-P is a suitable approach to allow for holistic insights into chromatin-associated changes between genotypes and treatments and to provide a suite of candidates that directs follow-up research.

\section{Methods}

Plant materials and growth conditions

Arabidopsis thaliana Col-0 was used as wild type in this study. The T-DNA insertion mutant al6 (SALK_ 040877C) was obtained from ABRC (Ohio State University, Columbus, OH, USA) and described previously [8]. Arabidopsis seeds were surface sterilized with 35\% bleach for $5 \mathrm{~min}$ and washed five times with sterile water ( $5 \mathrm{~min}$ each). Sterile seeds were placed on a growth medium described by Estelle and Somerville [13] composed of $5 \mathrm{mM} \mathrm{KNO}_{3}, 2 \mathrm{mM} \mathrm{MgSO}_{4}, 2 \mathrm{mM} \mathrm{Ca}\left(\mathrm{NO}_{3}\right)_{2}$, $2.5 \mathrm{mM} \mathrm{KH_{2 }} \mathrm{PO}_{4}, 70 \mu \mathrm{M} \mathrm{H} \mathrm{H}_{3} \mathrm{BO}_{3}, 14 \mu \mathrm{M} \mathrm{MnCl}_{2}, 1 \mu \mathrm{M}$ $\mathrm{ZnSO}_{4}, \quad 0.5 \mu \mathrm{M} \quad \mathrm{CuSO}_{4}, \quad 0.01 \mu \mathrm{M} \quad \mathrm{CoCl}_{2}, \quad 0.2 \mu \mathrm{M}$ $\mathrm{Na}_{2} \mathrm{MoO}_{4}$, and $40 \mu \mathrm{M}$ Fe-EDTA, and solidified with $0.4 \%$ Gelrite Pure. MES $(1 \mathrm{~g} / \mathrm{L})$ and $1.5 \%(w / v)$ sucrose were included, and the $\mathrm{pH}$ was adjusted to 5.5 with 


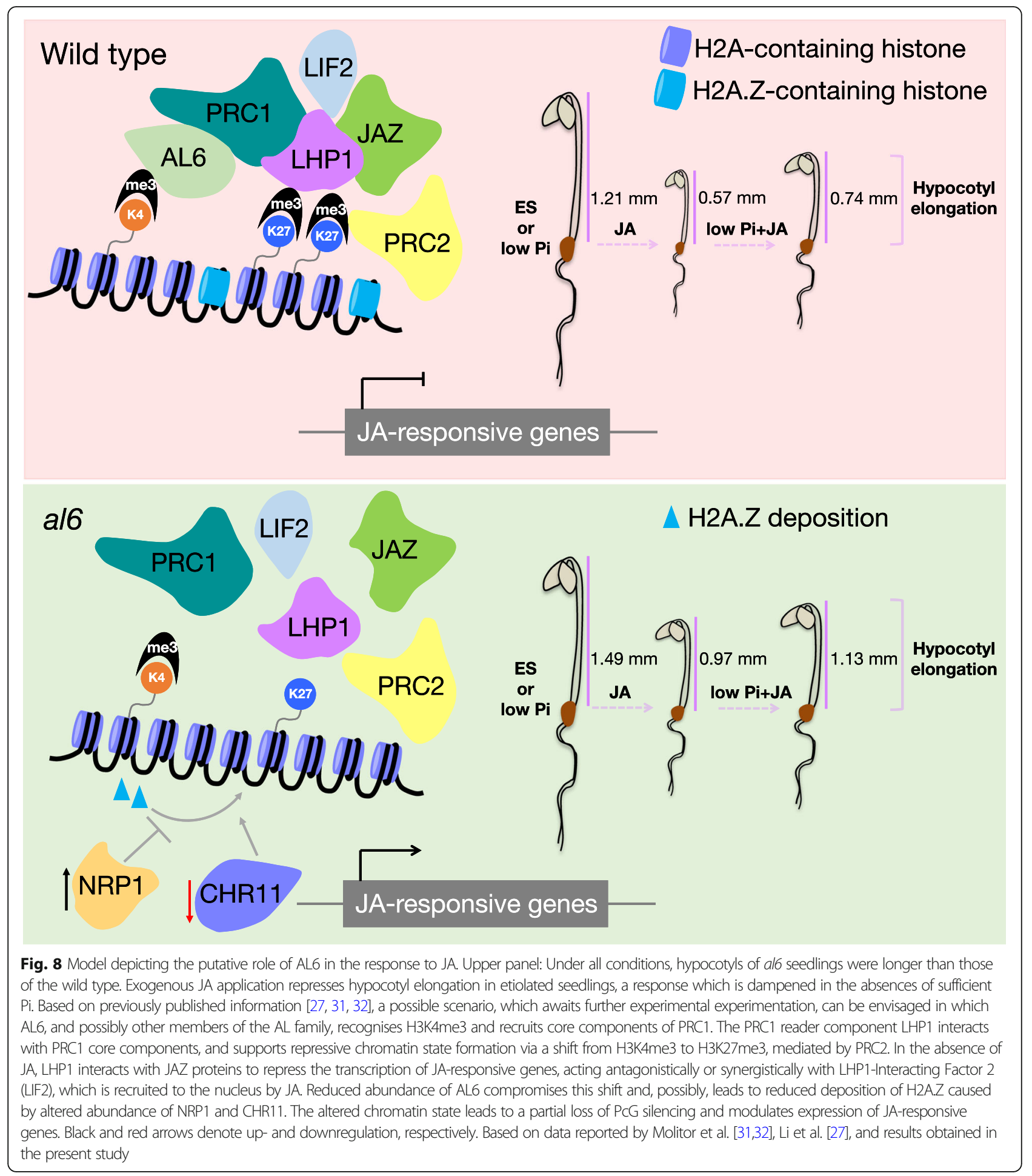

$\mathrm{KOH}$ (ES medium). Seeds were stratified on plates for 2 $\mathrm{d}$ at $4{ }^{\circ} \mathrm{C}$ in the dark, transferred to a growth chamber and grown at $22^{\circ} \mathrm{C}$ in the dark with $70 \%$ relative humidity. For low Pi-treated plants, media were supplemented

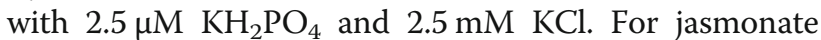
(JA) elicitation, seedlings were grown for 5 days on ES or low Pi medium containing $50 \mu \mathrm{M}$ JA. An equal amount of DMSO was added as a control in ES and low Pi plates.

The use of plant parts in the present study complies with international, national and institutional guidelines. 


\section{Plant imaging and hypocotyl measurement}

Images of 5-d-old seedlings were taken with a digital camera (Canon EOS 90D). The images included a ruler placed on top of the plate for further analysis. Hypocotyl lengths were measured with the ImageJ software (http:// rsb.info.nih.gov/ij) from a suite of 60 JPG images per replicate and treatment (three independent replicates) from seedlings grown on mock or low Pi media and media supplemented with $50 \mu \mathrm{M}$ JA. Graphs, calculations, and statistical analyses were performed using the GraphPad Prism software version 8.0 for Mac.

\section{Confocal laser and cryogenic scanning (cryo-SEM) microscopy and cell size measurements}

Etiolated hypocotyls were dipped in $10 \mu \mathrm{g} / \mathrm{mL}$ propidium iodide (PI) in $\mathrm{H}_{2} \mathrm{O}$ for $20 \mathrm{~min}$ in the dark, rinsed twice with $\mathrm{H}_{2} \mathrm{O}$ for $1 \mathrm{~min}$, and the PI fluorescence was visualized using a 20x objective on a Zeiss LSM880 confocal laser scanning microscope. For cryo-SEM, hypocotyls were frozen in liquid nitrogen before imaging. Images were obtained using a FEI Quanta 200 scanning electron microscope with cryo system (Quorum PP2000TR FEI) operating at an acceleration voltage of $3 \mathrm{kV}$. For cell size measurement, 30 cells of at least 10 etiolated hypocotyls for each treatment were used and processed using the ImageJ software. Statistical analysis was performed using the GraphPad Prism software version 8.0 for Mac.

\section{Jasmonate quantification}

For extraction of JA, etiolated hypocotyls ( $200 \mathrm{mg}$ fresh weight) were collected and frozen with liquid nitrogen. The ground tissue was dissolved in $550 \mu \mathrm{L}$ of working solution $\left(50 \mu \mathrm{L} \mathrm{MeOH}, 10 \mathrm{ng}\right.$ d5-JA, 2-propanol/ $\mathrm{H}_{2} \mathrm{O} /$ concentrated $\mathrm{HCl}, 2: 1: 0.002)$ and shaken at $100 \mathrm{rpm}$ for 30 min at $4{ }^{\circ} \mathrm{C}$. One $\mathrm{ml}$ of dichloromethane was added and shaken for $30 \mathrm{~min}$ at $4{ }^{\circ} \mathrm{C}$. The samples were centrifuged at $13,000 \mathrm{~g}$ for $5 \mathrm{~min}$ at $4{ }^{\circ} \mathrm{C}$, and $900 \mu \mathrm{L}$ of the lower phase was transferred to a fresh Eppendorf tube, desiccated for $40 \mathrm{~min}$ using nitrogen evaporate, and dissolved in $\mathrm{MeOH}$ for further analysis by liquid chromatographytandem mass spectrometry. Graphs, calculations, and statistical analyses were performed using the GraphPad Prism software version 8.0 for Mac.

\section{Gene ontology}

Gene ontology (GO) enrichment analysis of DEPs was performed using the Singular Enrichment Analysis (SEA) available on the ArgiGO v2.0 toolkit web-server [43]. The analysis was performed using the following parameters: selected species: Arabidopsis thaliana;

Reference: TAIR genome locus (TAIR10_2017); Statistical test method: Fisher; Multi-test adjustment method: Yekutieli (FDR under dependency); Significance level: 0.05; Minimum number of mapping entries: 5; Gene ontology type: Complete GO. Significantly enriched GO terms were summarized and visualized using REVIGO [42] with a similarity setting of 0.7 and SimRel as the semantic similarity measure. Final figures were plotted in $\mathrm{R}$ (version 3.6.2). Scatterplots show clusters that are representative of the distribution of GO terms represented as bubbles. Semantically similar GO terms will be closer together, the sizes of the bubbles indicate the frequency of GO term they represent. The gradient colour denotes the significance obtained from the enrichment analysis ( $\log 10 P$ value). Gene ontology enrichment for all proteins identified by ChEP-P in wild-type and al 6 mutant plants in at least in two biological repeats per treatment depicted as heatmaps was computed by TopGO using the Elim method [3] by implementation of GOBU (https://gobu.sourceforge.io/). Heatmaps were generated with the pheatmap package in $\mathrm{R}$

\section{Chromatin enrichment for proteomics in plants (ChEP-P)}

Chromatin samples were isolated from shoots of 5-dayold etiolated seedlings using a protocol adapted from Kustatscher et al. [22]. Briefly, $200 \mathrm{mg}$ of tissue were cross-linked with $10 \mathrm{~mL}$ buffer A $(0.4 \mathrm{M}$ sucrose, $10 \mathrm{mM}$ Tris pH $8,1 \mathrm{mM}$ EDTA, $1 \mathrm{mM}$ PMSF, 1\% formaldehyde) under vacuum for $20 \mathrm{~min}$ at room temperature. Crosslinking was quenched by adding $0.1 \mathrm{M}$ glycine for 10 min at room temperature [33]. The tissue was then washed trice with distilled water, incubated in $1 \mathrm{~mL}$ lysis buffer ( $25 \mathrm{mM}$ Tris pH 7.4, 0.1\% (v/v) Triton X-100, 85 $\mathrm{mM} \mathrm{KCl}$ and $2 \mathrm{X}$ Roche protease inhibitor tablets) for $15 \mathrm{~min}$ on ice, and centrifuged at $16,100 \mathrm{~g}$ for $35 \mathrm{~min}$ at $4{ }^{\circ} \mathrm{C}$. The nuclear pellet was resuspended in $500 \mu \mathrm{L}$ lysis buffer containing $200 \mu \mathrm{g} / \mathrm{mL}$ RNase A and incubated for $15 \mathrm{~min}$ at $37^{\circ} \mathrm{C}$. The pooled nuclei suspension was centrifuged at $16,100 \mathrm{~g}$ for $35 \mathrm{~min}$ at $4{ }^{\circ} \mathrm{C}$. The nuclei pellet was resuspended in $500 \mu \mathrm{L} 4 \%$ SDS buffer $(50 \mathrm{mM}$ Tris $\mathrm{pH}$ 7.4, $10 \mathrm{mM}$ EDTA, 4\% (w/v) SDS, $1 \mathrm{mM}$ PMSF, and $2 \mathrm{X}$ Roche protease inhibitor tablets), and incubated for $10 \mathrm{~min}$ at room temperature. A $1.5 \mathrm{~mL}$ aliquot of freshly prepared $8 \mathrm{M}$ urea buffer $(10 \mathrm{mM}$ Tris $\mathrm{pH} 7.4,1 \mathrm{mM}$ EDTA and $8 \mathrm{M}$ urea) were added to the sample, mixed by inverting the tube several times, and centrifuged at $16,100 \mathrm{~g}$ for $30 \mathrm{~min}$ at $25^{\circ} \mathrm{C}$. The supernatant was discarded, and the transparent pellet was washed twice with $500 \mu \mathrm{L}$ of $4 \%$ SDS buffer and centrifuged at $16,100 \mathrm{~g}$ for $25 \mathrm{~min}$ at $25^{\circ} \mathrm{C}$. Subsequently, the pellet was resuspended in $0.2 \mathrm{~mL}$ storage buffer $(10 \mathrm{mM}$ Tris $\mathrm{pH} 7.4,1$ mM EDTA, $25 \mathrm{mM} \mathrm{NaCl}, 10 \%$ (v/v) glycerol, $1 \mathrm{mM}$ PMSF, and 2X Roche protease inhibitor tablets). The sample was sonicated trice for $5 \mathrm{~min}$ on ice with an amplitude of $10 \%$ in alternating 'on' and 'off' intervals (30 s each), centrifuged at $16,100 \mathrm{~g}$ for $30 \mathrm{~min}$ at $4{ }^{\circ} \mathrm{C}$, and the supernatant containing the cross-linked chromatin was transfer to a new tube. 
On-bead trypsin digestion, quantitative label-free LC-MS/ MS analysis, and protein identification

Ten $\mu \mathrm{g}$ chromatin samples were digested with $12.5 \mu \mathrm{g}$ of modified trypsin (Promega) at $37^{\circ} \mathrm{C}$ overnight, and acidified with trifluoroacetic acid to a final concentration of $0.1 \%$. Samples containing the peptides were redissolved in solvent containing $0.1 \%$ formic acid and 3\% acetonitrile in water (J.T. Baker). The liquid chromatography on a Dionex UltiMate 3000 RSLCnano system coupled to a $\mathrm{Q}$ Exactive hybrid was performed and $3 \mu \mathrm{g}$ protein sample were injected for nano-HPLC-MS/MS analysis with an LC retention time alignment of $210 \mathrm{~min}$ from 5 to $40 \%$ solvent $\mathrm{A}$ at a flow rate of $300 \mathrm{nl} / \mathrm{min}$ per sample, samples were kept at $8{ }^{\circ} \mathrm{C}$ in the autosampler and the Q Exactive hybrid quadrupole-Orbitrap mass spectrometer in positive ionization mode was operated with a full scan $(\mathrm{m} / \mathrm{z} 350-1600)$ in the Orbitrap analyzer at resolution 70,000 , then the MS/MS of the ten most intense peptide ions was performed with $\mathrm{HCD}$ acquisition of the same precursor ion. The HCD was operated with collision energy of $30 \%$ and HCD-generated fragment ions in the Orbitrap were detected at resolution 17,500. For peptide quantification, three biological replicates were run trice, and label-free quantification was performed using the Proteome Discoverer ${ }^{\mathrm{Tm}}$ Software 2.2 (Thermo Fisher) using the Sequest search algorism. The Arabidopsis protein database (Araport11) was used to make the searches and was concatenated with a decoy database containing the randomized sequences of the original database. For each biological repeat, spectra from the three technical repeats were combined into one file and searched. The search parameters were as follows: trypsin was chosen as the enzyme with two missed cleavages allowed; fixed modifications of carbamidomethylation $(\mathrm{C})$ with variable modifications of Oxidation (M) and Acetyl (Protein Nterm); peptide tolerance was set at $10 \mathrm{ppm}$, and MS/MS tolerance was set at $0.05 \mathrm{Da}$. Peptide charge was set $\mathrm{M}_{\mathrm{r}}$, and monoisotopic mass is chosen. Label-free was chosen for quantitation during the search simultaneously. All peptide spectrum matches were filtered with a q-value threshold of 0.05 (5\% RDR), proteins were filtered with medium confidence threshold (0.05 q-value, 5\% FDR).

Due to the limited sensitivity of LC-MS/MS analysis, spectrum for the intensity of low abundant peptides may be zero [14]. Zero values from label-free mass spectrometry were analysed and normalized according to the maximum likelihood theory selection and exclusion of peptides and proteins as described by Karpievitch et al. [17]. For statistical analysis, the method described by Cox and Mann [12] was used. Log2 ratios were calculated for at least two biological repeats of the quantified proteins and analysed for normal distribution. For the mean and SD, 95\% confidence $(Z$ score $=1.96)$ was used to select proteins with a distribution far from the main distribution. Downregulated and upregulated proteins were calculated using a confidence interval of mean ratio $-1.96 \times \mathrm{SD}$ and $+1.96 \mathrm{x}$ SD, respectively.

\section{Abbreviations \\ ChEP-P: Chromatin enrichment for Proteomics in Plants; DEP: Differentially expressed proteins; PTM: Posttranslational modifications; PHD: plant homeodomain; SCF Coll: Skp-Cullin-F-box E3 ubiquitin ligase; PcG: Polycomb Group; PRC: PcG-Repressive Complex; Cryo-SEM: Cryogenic scanning microscopy; SEA: Singular Enrichment Analysis}

\section{Supplementary Information}

The online version contains supplementary material available at https://doi. org/10.1186/s12864-021-08160-6.

Additional file 1: Supplemental Fig. S1.

Additional file 2: Supplemental Fig. S2.

Additional file 3: Supplemental Fig. $\mathbf{S 3 .}$

Additional file 4: Supplemental Dataset S1.

Additional file 5: Supplemental Dataset S2.

Additional file 6: Supplemental Dataset S3.

\section{Acknowledgements}

We thank Mei-Jane Fang and Dr. Wann-Neng Jane from the IPMB Live Cell Imaging Core Laboratory for their help with confocal and cryo-SEM imaging, Drs. Tuan-Nan Wen and Chuan-Chih Hsu from the IPMB Proteomics Core Laboratory for their help with proteomic data analysis and Dr. Wendar Lin from the Bioinformatic Core Laboratory for help with GO enrichment analysis. Proteomic mass spectrometry analyses, in-gel digestion, and label-free quantification were performed by the Proteomics Core Laboratory sponsored by the Institute of Plant and Microbial Biology and the Agricultural Biotechnology Research Center, Academia Sinica. We also acknowledge the Metabolomics Core Laboratory at ABRC, Academia Sinica, for providing help with JA analysis. I.C.V-B was supported by fellowships provided by the Ministry of Science and Technology (MOST) and Academia Sinica.

\section{Authors' contributions}

I.C.V-B. performed the experiments; I.C.V-B. and W.S. conceived the project, analysed the data, and wrote the manuscript. All authors read and approved the final manuscript.

\section{Funding}

Work in the Schmidt laboratory is funded by Academia Sinica and the Ministry of Science and Technology.

\section{Availability of data and materials}

The mass spectrometry proteomics data have been deposited to the ProteomeXchange Consortium via the PRIDE [37] partner repository with the dataset identifier PXD02654.

Username: reviewer_pxd026541@ebi.ac.uk

Password: 17n2gfYP.

\section{Declarations}

Ethics approval and consent to participate Not applicable.

Consent for publication

Not applicable.

\section{Competing interests}

The authors declare that they have no competing interests.

\section{Author details}

${ }^{1}$ Institute of Plant and Microbial Biology, Academia Sinica, Taipei 11529

Taiwan. ${ }^{2}$ Biotechnology Center, National Chung-Hsing University, Taichung 
40227, Taiwan. ${ }^{3}$ Genome and Systems Biology Degree Program, College of Life Science, National Taiwan University, Taipei 10617, Taiwan.

\section{Received: 30 June 2021 Accepted: 8 November 2021} Published online: 22 November 2021

\section{References}

1. Aasland R, Gibson TJ, Stewart AF. The PHD finger: implications for chromatin-mediated transcriptional regulation. Trends Biochem Sci. 1995; 20(2):56-9. https://doi.org/10.1016/S0968-0004(00)88957-4.

2. Aguilar-Hernández V, Kim D, Stankey RJ, Scalf M, Smith LM, Vierstra RD. Mass spectrometric analyses reveal a central role for ubiquitylation in remodeling the Arabidopsis proteome during photomorphogenesis. Mol Plant. 2017; 10(6):846-65. https://doi.org/10.1016/j.molp.2017.04.008.

3. Alexa A, Rahnenführer J, Lengauer T. Improved scoring of functional groups from gene expression data by decorrelating GO graph structure. Bioinformatics. 2006;22(13):1600-7. https://doi.org/10.1093/bioinformatics/ btl140.

4. Bastola DR, Pethe W, Winicov I. Alfin1, a novel zinc-finger protein in alfalfa roots that binds to promoter elements in the salt-inducible MsPRP2 gene. Plant Mol Biol. 1998;38(6):1123-35. https://doi.org/10.1023/A:1006081926699.

5. Batugedara G, Lu XM, Saraf A, Sardiu ME, Cort A, Abel S, et al. The chromatin bound proteome of the human malaria parasite. Microb Genom. 2020;6(2):e000327. https://doi.org/10.1099/mgen.0.000327.

6. Beauchemin M, Morse D. A proteomic portrait of dinoflagellate chromatin reveals abundant RNA-binding proteins. Chromosoma. 2018;127(1):29-43. https://doi.org/10.1007/s00412-017-0643-8.

7. Carter B, Bishop B, Ho KK, Huang R, Jia W, Zhang H, et al. The chromatin remodelers PKL and PIE1 act in an epigenetic pathway that determines H3K27me3 homeostasis in Arabidopsis. Plant Cell. 2018;30(6):1337-52. https://doi.org/10.1105/tpc.17.00867.

8. Chandrika NNP, Sundaravelpandian K, Yu SM, Schmidt W. ALFIN-LIKE 6 is involved in root hair elongation during phosphate deficiency in Arabidopsis. New Phytol. 2013;198(3):709-20. https://doi.org/10.1111/ nph.12194.

9. Chen CY, Schmidt W. The paralogous R3 MYB proteins CAPRICE, TRIPTYCHON and ENHANCER OF TRY AND CPC1 play pleiotropic and partly non-redundant roles in the phosphate starvation response of Arabidopsis roots. J Exp Bot. 2015;66(15):4821-34. https://doi.org/10.1093/jxb/erv259.

10. Chini A, Fonseca SGDC, Fernandez G, Adie B, Chico JM, Lorenzo O, et al. The JAZ family of repressors is the missing link in jasmonate signalling. Nature. 2007:448(7154):666-71. https://doi.org/10.1038/nature06006.

11. Choi K, Park C, Lee J, Oh M, Noh B, Lee I. Arabidopsis homologs of components of the SWR1 complex regulate flowering and plant development. Development. 2007;134(10):1931-41. https://doi.org/10.1242/ dev.001891.

12. Cox J, Mann M. MaxQuant enables high peptide identification rates, individualized p.p.b.-range mass accuracies and proteome wide protein quantification. Nat Biotechnol. 2008;26:1367-72.

13. Estelle MA, Somerville C. Auxin-resistant mutants of Arabidopsis thaliana with an altered morphology. Mol Genet Genomics. 1987;206(2):200-6. https://doi.org/10.1007/BF00333575.

14. Graw S, Tang J, Zafar MK, Byrd AK, Bolden C, Peterson EC, et al. proteiNormA user-friendly tool for normalization and analysis of TMT and label-free protein quantification. ACS Omega. 2020;5(40):25625-33. https://doi.org/10.1 021/acsomega.0c02564.

15. Huang H, Liu B, Liu L, Song S. Jasmonate action in plant growth and development. J Exp Bot. 2017;68(6):1349-59. https://doi.org/10.1093/jxb/ erw495.

16. Iglesias J, Trigueros M, Rojas-Triana M, Fernández M, Albar JP, Bustos R, et al. Proteomics identifies ubiquitin-proteasome targets and new roles for chromatin-remodeling in the Arabidopsis response to phosphate starvation. J Proteom. 2013;94:1-22. https://doi.org/10.1016/j.jprot.2013.08.015.

17. Karpievitch $\mathrm{W}$, Dabney AR, Smith RD. Normalization and missing value imputation for label-free LC-MS analysis. BMC Bioinformatics. 2012;13(S16): 1-9. https://doi.org/10.1186/1471-2105-13-S16-S5.

18. Katsir L, Schilmiller AL, Staswick PE, He SY, Howe GA. COI1 is a critical component of a receptor for jasmonate and the bacterial virulence factor coronatine. Proc Natl Acad Sci U S A. 2008;105(19):7100-5. https://doi.org/1 0.1073/pnas.0802332105.
19. Khan GA, Vogiatzaki E, Glauser G, Poirier Y. Phosphate deficiency induces the jasmonate pathway and enhances resistance to insect herbivory. Plant Physiol. 2016;171(1):632-44. https://doi.org/10.1104/pp.16.00278.

20. Kito Y, Matsumoto M, Hatano A, Takami T, Oshikawa K, Matsumoto A, et al. Cell cycle-dependent localization of the proteasome to chromatin. Sci Rep. 2020;10:1-17.

21. Kustatscher G, Grabowski P, Rappsilber J. Multiclassifier combinatorial proteomics of organelle shadows at the example of mitochondria in chromatin data. Proteomics. 2016;16(3):393-401. https://doi.org/10.1002/ pmic.201500267.

22. Kustatscher G, Wills KL, Furlan C, Rappsilber J. Chromatin enrichment for proteomics. Nat Protoc. 2014;9(9):2090-9. https://doi.org/10.1038/nprot.2 014.142.

23. Le Roux C, Del Prete S, Boutet-Mercey S, Perreau F, Balague C, Roby D, et al. The hnRNP-Q protein LIF2 participates in the plant immune response. PLoS One. 2014;9(6):e99343. https://doi.org/10.1371/journal.pone.0099343.

24. Lee WY, Lee D, Chung WI, Kwon CS. Arabidopsis ING and Alfin1-like protein families localize to the nucleus and bind to H3K4me3/2 via plant homeodomain fingers. Plant J. 2009;58(3):511-24. https://doi.org/10.1111/ j.1365-313X.2009.03795.x.

25. Li H, Luan S. The cyclophilin AtCYP71 interacts with CAF-1 and LHP1 and functions in multiple chromatin remodeling processes. Mol Plant. 2011;4(4): 748-58. https://doi.org/10.1093/mp/ssr036.

26. Li S, Liu K, Zhou B, Li M, Zhang S, Zeng L, et al. MAC3A and MAC3B, two core subunits of the MOS4-associated complex, positively influence miRNA biogenesis. Plant Cell. 2018;30(2):481-94. https://doi.org/10.1105/tpc.17.00953.

27. Li Z, Luo $X$, Ou Y, Jiao H, Peng L, Fu X, et al. JASMONATE-ZIM DOMAIN proteins engage Polycomb chromatin modifiers to modulate Jasmonate signaling in Arabidopsis. Mol Plant. 2021;14(5):732-47. https://doi.org/10.101 6/j.molp.2021.03.001

28. Liang X, Lei M, Li F, Yang X, Zhou M, Li B, et al. Family-wide characterization of histone binding abilities of PHD domains of AL proteins in Arabidopsis thaliana. Protein J. 2018;37(6):531-8. https://doi.org/10.1007/s10930-0189796-4.

29. Luo YX, Hou XM, Zhang CJ, Tan LM, Shao CR, Lin RN, et al. A plant-specific SWR1 chromatin-remodeling complex couples histone H2A. Z deposition with nucleosome sliding. EMBO J. 2020;39:e102008.

30. Martire S, Banaszynski LA. The roles of histone variants in fine-tuning chromatin organization and function. Nat Rev Mol Cell Biol. 2020;21(9):52241. https://doi.org/10.1038/s41580-020-0262-8.

31. Molitor AM, Bu Z, Yu Y, Shen WH. Arabidopsis AL PHD-PRC1 complexes promote seed germination through H3K4me3-to-H3K27me3 chromatin state switch in repression of seed developmental genes. PLoS Genet. 2014; 10(1):e1004091. https://doi.org/10.1371/journal.pgen.1004091.

32. Molitor AM, Latrasse D, Zytnicki M, Andrey P, Houba-Hérin N, Hachet M, et al. The Arabidopsis hnRNP-Q protein LIF2 and the PRC1 subunit LHP1 function in concert to regulate the transcription of stress-responsive genes. Plant Cell. 2016;28(9):2197-211. https://doi.org/10.1105/tpc.16.00244.

33. Morohashi K, Zhao M, Yang M, Read B, Lloyd A, Lamb R, Grotewold E. Participation of the Arabidopsis bHLH factor GL3 in trichome initiation regulatory events. Plant Physiol. 2007;145(3):736-46. https://doi.org/10.1104/ pp.107.104521.

34. Monaghan J, Xu F, Gao M, Zhao Q, Palma K, Long C, et al. Two Prp19-like Ubox proteins in the MOS4-associated complex play redundant roles in plant innate immunity. PLoS Pathog. 2009;5(7):e1000526. https://doi.org/10.1371/ journal.ppat.1000526.

35. Palma K, Zhao Q, Cheng YT, Bi D, Monaghan J, Cheng W, et al. Regulation of plant innate immunity by three proteins in a complex conserved across the plant and animal kingdoms. Genes Dev. 2007;21(12):1484-93. https:// doi.org/10.1101/gad.1559607.

36. Pauwels L, Barbero GF, Geerinck J, Tilleman S, Grunewald W, Pérez AC, et al. NINJA connects the co-repressor TOPLESS to jasmonate signalling. Nature. 2010;464(7289):788-91. https://doi.org/10.1038/nature08854.

37. Perez-Riverol Y, Csordas A, Bai J, Bernal-Llinares M, Hewapathirana S, Kundu DJ, et al. The PRIDE database and related tools and resources in 2019: improving support for quantification data. Nucleic Acids Res. 2019;47(D1): D442-50. https://doi.org/10.1093/nar/gky1106.

38. Reichel $M$, Liao $Y$, Rettel $M$, Ragan C, Evers M, Alleaume AM, et al. In planta determination of the mRNA-binding proteome of Arabidopsis etiolated seedlings. Plant Cell. 2016;8(10):2435-52. https://doi.org/10.1105/tpc.16. 00562. 
39. Smith AP, Jain A, Deal RB, Nagarajan VK, Poling MD, Raghothama KG, et al. Histone H2A.Z regulates the expression of several classes of phosphate starvation response genes but not as a transcriptional activator. Plant Physiol. 2010;152(1):217-25. https://doi.org/10.1104/pp.109.145532.

40. Strahl $B D$, Allis CD. The language of covalent histone modifications. Nature. 2000:403(6765):41-5. https://doi.org/10.1038/47412.

41. Suen DF, Tsai YH, Cheng YT, Radjacommare R, Ahirwar RN, Fu H, et al. The deubiquitinase OTU5 regulates root responses to phosphate starvation. Plant Physiol. 2018;176(3):2441-55. https://doi.org/10.1104/pp.17.01525.

42. Supek F, Bošnjak M, Škunca N, Šmuc T. REVIGO summarizes and visualizes long lists of gene ontology terms. PLoS One. 2011;6(7):e21800. https://doi. org/10.1371/journal.pone.0021800.

43. Tian T, Liu Y, Yan H, You Q, Yi X, Du Z, et al. agriGO v2.0: a GO analysis toolkit for the agricultural community. Nucleic Acids Res. 2017;45(W1):122-9. https://doi.org/10.1093/nar/gkx382.

44. Ueda M, Seki M. Epigenetic networks for abiotic stress response. Plant Physiol. 2019;182(1):15-26. https://doi.org/10.1104/pp.19.00988.

45. Van Mierlo GV, Wester RA, Marks H. A mass spectrometry survey of chromatin-associated proteins in pluripotency and early lineage commitment. Proteomics. 2019;19(14):e1900047. https://doi.org/10.1002/ pmic.201900047.

46. Wang $Y$, Zhong Z, Zhang $Y, X u L$, Feng $S$, Rayatpisheh $S$, et al. NAP1RELATED PROTEIN 1 and 2 negatively regulate H2A.Z abundance in chromatin in Arabidopsis. Nat Commun. 2020;11:2887.

47. Wu K, Zhang L, Zhou C, Yu CW, Chaikam V. HDA6 is required for jasmonate response, senescence and flowering in Arabidopsis. J Exp Bot. 2008;59(2): 225-34. https://doi.org/10.1093/jxb/erm300.

48. Wu X, Shi Y, Li J, Xu L, Fang Y, Li X, et al. A role for the RNA-binding protein MOS2 in microRNA maturation in Arabidopsis. Cell Res. 2013;23(5):645-57. https://doi.org/10.1038/cr.2013.23.

49. Yu CW, Liu X, Luo M, Chen C, Lin X, Tian G, et al. HISTONE DEACETYLASE6 interacts with FLOWERING LOCUS D and regulates flowering in Arabidopsis. Plant Physiol. 2011;156(1):173-84. https://doi.org/10.1104/pp.111.174417.

50. Zhang S, Liu Y, Yu B. PRL1, an RNA-binding protein, positively regulates the accumulation of miRNAs and siRNAs in Arabidopsis. PLoS Genet. 2014; 10(12):e1 004841. https://doi.org/10.1371/journal.pgen.1004841.

51. Zhang S, Xie M, Ren G, Yu B. CDC5, a DNA binding protein, positively regulates posttranscriptional processing and/or transcription of primary microRNA transcripts. Proc Natl Acad Sci U S A. 2013:110:17588-93.

52. Zhang Y, Cheng YT, Bi D, Palma K, Li X. MOS2, a protein containing G-patch and KOW motifs, is essential for innate immunity in Arabidopsis thaliana. Curr Biol. 2005;15(21):1936-42. https://doi.org/10.1016/j.cub.2005.09.038.

53. Zhao S, Zhang B, Yang M, Zhu J, Li H. Systematic profiling of histone readers in Arabidopsis thaliana. Cell Rep. 2018;22(4):1090-102. https://doi. org/10.1016/j.celrep.2017.12.099.

54. Zheng Y, Cui X, Su L, Fang S, Chu J, Gong Q, et al. Jasmonate inhibits COP 1 activity to suppress hypocotyl elongation and promote cotyledon opening in etiolated Arabidopsis seedlings. Plant J. 2017;90(6):1144-55. https://doi. org/10.1111/tpj.13539.

55. Zhou C, Zhang L, Duan J, Miki B, Wu K. HISTONE DEACETYLASE19 is involved in jasmonic acid and ethylene signaling of pathogen response in Arabidopsis. Plant Cell. 2005;17(4):1196-04. https://doi.org/10.1105/tpc.104. 028514 .

\section{Publisher's Note}

Springer Nature remains neutral with regard to jurisdictional claims in published maps and institutional affiliations.

Ready to submit your research? Choose BMC and benefit from:
- fast, convenient online submission
- thorough peer review by experienced researchers in your field
- rapid publication on acceptance
- support for research data, including large and complex data types
- gold Open Access which fosters wider collaboration and increased citations
- maximum visibility for your research: over 100M website views per year
At BMC, research is always in progress.
Learn more biomedcentral.com/submissions

